\title{
Analytical Applications of Neutron Capture Gamma-Ray Spectroscopy
}

\author{
A. M. Hassan, E. Gantner, E. Mainka \\ H. Ruf, U. Kuhnes, M. Mostafa \\ Institut für Radiochemie
}


KERNFORSCHUNGS ZENTRUM KARLSRUHE

Institut für Radiochemie

KfK 3387

Analytical Applications of Neutron

Capture Gamma-Ray Spectroscopy

A.M. Hassan ${ }^{+)}$, E. Gantner, E. Mainka,

H. Ruf, U. Kuhnes and M. Mostafa

Kernforschungszentrum Karlsruhe $\mathrm{GmbH}$, Karlsruhe

+) On leave from: Reactor and Neutron Phys. Dept., Nucl. Research Centre, Atomic Energy Establishment (Inchass), Atomic Energy Post Office Cairo, EGYPT. 
Als Manuskript vervielfältigt

Für diesen Bericht behalten wir uns alle Rechte vor

Kernforschungszentrum Karlsruhe $\mathrm{GmbH}$

ISSN 0303-4003 
Analytical applications of neutron capture gamma-ray spectroscopy

Abstract: Prompt gamma-rays from thermal induced nuclear reactions have been used to estimate the boron, chlorine and phosphorus contents in industrial and reference materials.

A neutron capture gamma-ray spectroscopy facility for analytical purposes using 252-Cf sources has been designed and calibrated. The facility is principally designed for the measurement of the prompt gamma-ray spectra obtained due to thermal neutron capture by means of the internal target geometry. The capture spectra were recorded using a high resolution Ge(Li) system. The designed facility and the system used in this work are described in detail.

A weight of 50 to $100 \mathrm{gm}$ of each sample in a powder or liquid form encapsulated in a polyethene container was used.

Sensitivity curves using different standard concentration values of $\mathrm{B}, \mathrm{Cl}$ and $\mathrm{P}$, were constructed. The concentration range was from 0.005 to $30 \%$ 
Analytische Anwendungen der Spektroskopie prompter Gamma-Strahlung beim Neutronen-Einfang

Zusammenfassung: Mit Hilfe der beim thermischen Neutroneneinfang prompt emittierten $\gamma$-strahlung wurden Gehalte an Bor, Chlor und Phosphor in verschiedenen industriellen Produkten sowie in Standardproben bestimmt.

Eine entsprechende, für analytische Zwecke geeignete Versuchsanordnung mit $\mathrm{Cf}-252$ als Neutronenquelle wurde gebaut und geeicht. Die Anordnung ist so ausgelegt, daß die beim thermischen Neutroneneinfang prompt emittierte $\gamma$-Strahlung unter Anwendung der "internal target"-Geometrie gemessen wird. Die Einfangsspektren wurden mit einem hochauflösenden Ge(Li)-System aufgenommen. Die verwendete Bestrahlungseinrichtung und die Meßanordnung werden im Detail beschrieben.

Als Meßproben wurden Pulver oder Flüssigkeiten mit einem Gewicht von 50 bis 100 Gramm in Polyaethylenflaschen benutzt.

Eichkurven für verschiedene Standardkonzentrationen für Bor, Chlor und Phosphor wurden erstellt. Die untersuchten Konzentrationen lagen zwischen $0,005 \%$ und $30 \div$ 
1. Introduction $\ldots \ldots \ldots \ldots \ldots \ldots \ldots \ldots \ldots \ldots \ldots \ldots$

2. Experimental ........................ 2

2.1 Prompt Gamma-Ray Neutron Activation Analysis Assembly ................... 2

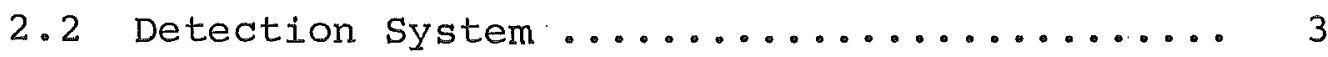

2.3 Energy Calibration ................. 4

3. Results and Discussions ................ 4

3.1 Boron Determination. ................ 4

3.2 Chlorine Determination .............. 6

3.3 Phosphorus Determination .............. 7

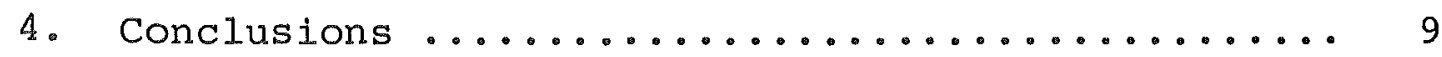

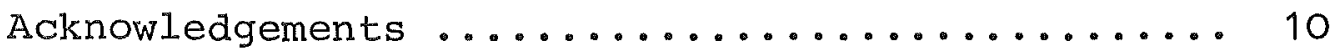

References $\ldots \ldots \ldots \ldots \ldots \ldots \ldots \ldots \ldots \ldots \ldots \ldots \ldots$

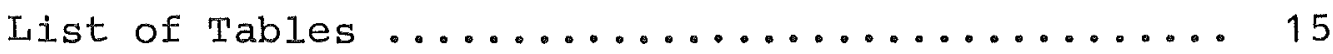

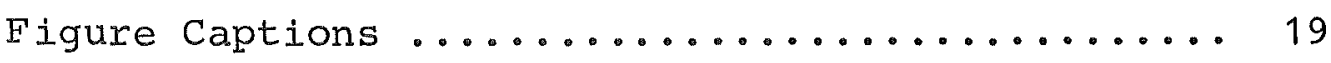


1. INTRODUCTION

The principle of the neutron capture gamma-ray technique involves the measurement of characteristic gamma-rays which follow the absorption of thermal neutrons. This provides information on some nuclear data such as the level schemes of particular nuclei, and can offer a nondestructive analytical technique. The technique is commonly known as Prompt Gamma-Ray Neutron Activation Analysis (PGNAA).

The extensive development and application of the PGNAA technique as a useful research tool for the study of multielemental characterization of complex samples has largely occurred within the past 15 years. Literature surveys by recent articles $(1-12)$ have revealed that some hundreds of papers utilizing this technique have been published within this period.

The main advantages of this technique over the other conventional techniques are the ability to measure instantaneously, simultaneously and nondestructively, the major elements in most materials and several important minor and trace elements. Also the low residual activity, bulk sample analyses and the high accuracy for short lived elements are improved $(13-16)$.

Various approaches have been used for exploitation of neutron capture prompt gamma-rays in multielemental analytical work using research reactors or isotopic neutron sources as sources of thermal neutrons. Reactor-based neutron sources generally provide much higher sensitivity for particular applications which can be performed in a laboratory environment. The portable neutron sources, both isotopic and neutron generators, offer a wide range of industrial and field applications with some lower sensitivities.

Two distinct geometrical arrangements of target and detector are possible. One can use either the internal target geometry by placing the sample inside the reactor or the assembly used and observe the gamma-rays outside of these facilities, or the external target geometry by bringing a neutron beam outside to a sample mounted close to the detector. The internal geometry has the advantage of high neutron flux but poor counting geometry. In the case of external geometry, it is just the opposite. 
The theoretical basis and design considerations of the PGNAA facilities using such different methods have been reviewed recently by different authors $(17-20)$. This work deals with the practical applications concerning the use of thermal neutron capture gamma-rays for estimation of boron, chlorine and phosphorus contents in industrial and reference materials. A Ge(Li) detection system and a 252-CI neutron source based PGNAA facility with the internal target geometry were used.

\section{EXPERIMENTAL}

2.1 Prompt Gamma-Ray Neutron Activation Analysis Assembly: An assembly has been designed in the form of a cubic container of paraffin and plexiglass moderators with volume of $1 \mathrm{~m}^{3}$, as shown in fig. (1-a). At the axial centre of this container the two 252-Cf neutron sources of 27 and $15 \mu \mathrm{gm}$ and the sample (polyethene container of $100 \mathrm{ml}$ ) were placed as shown in figs. ( $1-\mathrm{b}$ and $1-\mathrm{c})$. Two rectangular plexiglass holders for the neutron sources and the sample with dimensions of $200 \mathrm{~mm}, \mathrm{H} . \times 200 \mathrm{~mm}, \mathrm{w}_{0} \times 500 \mathrm{~mm}$, L. for each, were prepared to slide easily at the axial centre of the assembly. The two neutron sources were fixed at the inner end of the source-holder in $12 \mathrm{~mm}$ diameter holes on both sides, $150 \mathrm{~mm}$ apart. A hole with diameter of $30 \mathrm{~mm}$ at the inner end of the sample-holder is used for placing the sample container. It is designed to be equidistant from the positions of the two neutron sources as shown in fig. (1-c). This position was chosen in order to increase the neutron flux density at the target position. Changing the sample under investigation or removing the neutron sources is easily accomplished by sliding smoothly the two holders on both sides. The prompt gamma-rays emitted from the samples under investigation due to thermal neutron capture were collimated 
to the Ge(Li) detector in such a way that the background coming from the neutron sources is not seen by it. A gammaray collimator of lead was designed in a cylindrical form as shown in fig. (1-d) for this purpose. Its dimensions were $150 \mathrm{~mm}, \varnothing, \times 400 \mathrm{~mm}, I$, with an aperture of $50 \mathrm{~mm} \phi$ close to the sample position and ended by an aperture of $100 \mathrm{~mm}, \varnothing$ covering the Ge( $L i)$ detector. A sheath of lead with $300 \mathrm{~mm}$ I x $300 \mathrm{~mm}$, W. X $25 \mathrm{~mm}$ thickness and with central aperture of $50 \mathrm{~mm} \phi$ was positioned on the top of collimator. This lead sheath and the wall of the collimator were serving as a neutron shadow shield. At the upper end of the collimator, a polyethene plug with $50 \mathrm{~mm}, \varnothing \mathrm{x} 50 \mathrm{~mm} \mathrm{~L}$ was positioned to minimize the intensity of the scattered neutrons from the samples. The distance between the sample position and the detector was $300 \mathrm{~mm}$. This distance was chosen to expose the detector to the minimum possible scattered neutron intensity. The Ge(Li) detector used was covered by a closed end jacket of boron carbide of $10 \mathrm{~mm}$ thickness which was lined internally with a cadmium sheath of $1 \mathrm{~mm}$ thickness. This screen of $\mathrm{B}_{4} \mathrm{C}$ and $\mathrm{Cd}$ is used for the protection of the detector against scattered neutrons.

The neutron flux density was measured at the target and the detector positions using gold foil and dysprosium (as $\mathrm{Dy}_{2} \mathrm{O}_{3}$ powder) techniques. It was about $3 \times 10^{5} \mathrm{n} / \mathrm{cm}^{2}$. sec at the target position. At the detector position the neutron flux was too low to be detected.

Photographs of the PGNAA facility showing a side view, sample position, detector position and overall view are presented in figs. ( $2 \mathrm{a}, \mathrm{b}, \mathrm{c}$ and $\mathrm{d}$ ).

\subsection{Detection System:}

A closed end coaxial Ge(Li) detector with a relative efficiency of $13.5 \%$ and resolution of $1.95 \mathrm{keV}$ FWHM at $1332 \mathrm{keV}$ is used for gamma-ray detection. Signals from the detector 
were passed through a FET preamplifier to be amplified by a spectroscopy amplifier which fed directly to the 4096 multichannel analyzer. The output data from the analyzer were printed out and analyzed graphically.

\subsection{Energy Calibration:}

In order to establish the low and high energy scales up to $9000 \mathrm{keV}$, a group of sharp and well resolved prompt gamma-ray lines of photo, single $(/)$ and double $(/ /)$ escape peaks of $\mathrm{H}, \mathrm{C}, \mathrm{Fe}$ and $\mathrm{Pb}$ observed as background in the spectra obtained have been used. A simple computer program was established for this purpose (the accuracy was $0.2 \mathrm{keV}$ ). The gamma-ray energies used $(21-23)$ are listed in Table 1.

\section{RESULTS AND DISCUSSIONS}

The results of the measurements done for boron, chlorine and phosphorus are presented in this section. The analytical results and comparisons with past measurements are compiled under different subsections for each element.

\subsection{Boron Determination:}

Boron is commercially important as a metallurgical additive and fertilizer component. It is also commonly used in the home for laundary and cleaning purposes $(24-29)$. It has as well an important role in the glass industry and is used for: safety purposes in the nuclear industry.

B-10 occuring in natural boron with an abundance of $19.6 \%$, has an exceptionally large cross-section for thermal neutron capture (3837 barns) (30). Only two $\alpha$-particle energy groups are emitted when boron is irradiated with thermal neutrons. 
One $\alpha$-particle group decays directly to the ground state of ${ }^{7} \mathrm{Li}$, while the other group decays to the $478 \mathrm{keV}$ excited state of ${ }^{7} \mathrm{Li}$. Most of the ${ }^{7} \mathrm{Li}$ (93. \%) produced by ${ }^{10} \mathrm{~B}(n, \alpha){ }^{7} \mathrm{Li}$ reaction is in an excited state which decays within $5 \times 10^{-14}$ sec. emitting a $478 \mathrm{kgeV}$ gamma-ray. Since the gamma-ray is emitted while the recoiling ${ }^{7} \mathrm{Li}$ nucleus is in flight, it is Doppler-broadened in a distinctive rectangular energy distribution.

Accordingly, boron concentration values in compounds can be determined with the aid of thermal neutron capture gammarays as ${ }^{10}{ }_{B}$ undergoes an $(n, \alpha)$ reaction producing ${ }^{7} \mathrm{~L}$. For calibration purposes, liquid samples of different boron content of $\left(\mathrm{H}_{3} \mathrm{BO}_{3}\right.$ dissolved in distilled $\left.\mathrm{H}_{2} \mathrm{O}\right)$ can be used. A set of prompt gamma-ray spectra resulting from thermal neutron irradiation of $100 \mathrm{ml}$ samples has been recorded. The boron concentration values were $0.0,0.01,0.05,0.10$, $0.25,0.50,0.75$ and $1.00 \%$. The spectrum has been collected for 4000 seconds for each sample. In fig. (3), the Doppler-shifted boron gamma-ray peaks at $478 \mathrm{keV}$ have been plotted for each concentration value.

The net peak area values of the $478 \mathrm{keV}$ gamma-ray lines have been plotted against the concentration percentage values of boron (in the range between $O$ and $1.0 \%$ ) as shown in fig. (4a). This calibration curve could be used for the determination of the boron concentration values for similar material under the same conditions.

It was also of interest to check the applicability of this method for determination of boron concentration values in pyrexborosilicate glass, Duran-50, G-20 and Raschig Rings as industrial materials used in our laboratories. In this case, the calibration curves have been established using $\mathrm{B}_{4} \mathrm{C}$ powder samplesmixed with pure sea sand. The boron concentrations in the samples used were: $0.00,0.007,0.010,0.025$, $0.050,0.075$ and $0.100 \%$ A $100 \mathrm{gm}$ of material was used in 
each sample. The low percentages have been used in order to avoid the self-absorption saturation region shown before in fig. (4.a). The prompt gamma-ray spectrum for each sample has been collected for 4000 seconds and the results of the net peak area values under the $478 \mathrm{keV}$ line were plotted against the concentration values as shown in fig. $(4, b)$.

Samples of pyrexborosilicate glass, Duran-50, G-20 and Raschig Rings, have been prepared in a powder form ( 200 mesh) and mixed with sea sand material (1: 100). A $100 \mathrm{gm}$ amount of each mixed sample was measured under the same conditions as mentioned above. The results obtained are presented in table 2 as real percentage values. The table shows also a comparison between these values and the industrial certified values of boron content (31).

From table 2, one can notice fairly good agreement between the results of the present work and those which are certified by the industrial reports, taking into consideration the experimental statistical error ( $5 \%$ ). A slight increase in these values might be expected due to the Na gamma-ray line which is supposed to appear at $472 \mathrm{keV}$. In fact, such a line was not clear in the prompt gamna-ray spectra obtained. In case of measuring the boron content values, the boron carbide jacket which covers the Ge(Li) detector is replaced by another one made of $\mathrm{Cd}$ only, in order to avoid the boron background error.

\subsection{Chlorine Determination:}

As an analytical application of the PGNAA method, the nondestructive determination of chlorine content using sodium chloride solutions was carried out.

Chlorine-35 isotope has an abundance of $75.7 \%$ in natural chlorine $(30)$ and a high cross-section for thermal neutron capture (43 barns). In comparison, the relative neutron capture by the sodium in the sample is small ${ }^{(30)},(1.6 \%$ of the 
total).

Accoxdingly, one can expect to observe easily the ${ }^{36} \mathrm{Cl}$ gamma-ray lines in NaCl spectra. These lines can be used to obtain the chlorine concentration values in such a sample.

Different amounts of $\mathrm{NaCl}$ samples were dissolved in distilled water with the aim of preparation of solutions with the following chlorine concentration values, $0.0,1.0,2.5,5.0$, $10.0,15.0$ and $20 \%$. A volume of $100 \mathrm{ml}$ of each sample was used for the measurement of the prompt gamma-ray spectra using the PGNAA facility described above, for: Ooo second runs. A typical example of a spectrum is shown in figs. 5.a, 5.b, 5.c and $5 . d$ for one of these samples of $10 \%$ chlorine in the energy region 500 up to $9000 \mathrm{keV}$. The spectra obtained were more satisfactory over the whole energy region. The single and double escape peaks at high energy values (above 2 ooo kev) could be noticed. The main background lines of $\mathrm{H}, \mathrm{C}, \mathrm{Fe}$ and $\mathrm{Pb}$ appeared without any interference with the chlorine lines. More than 27 gamma-ray lines of chlorine (21-23) could be recognized. The best resolved lines at $789,1165,2864,5715,7790$ and $8579 \mathrm{keV}$ have been selected to establish the different calibration curves shown in figs. 6.a, 6.b, 6.c, 6.d, 6.e and 6. I, which could be used for determination of chlorine under the same experimental conditions. Due to self absorption, a saturation region appeared at high concentration values from 5 to $20 \%$.

\subsection{Phosphorus Determination:}

In the Exame of programmes in IRCH - KFK which deal with the recovery of phosphorus from industrial waters using $\mathrm{Al}_{2} \mathrm{O}_{3}$ filter systems, and in lime samples, the phosphorus content of such materials have to be determined routinely. It was, therefore, of interest to check the applicability of the PGNAA 
as a fast and nondestructive method for the determination of phosphorus in these samples which could not be determined by means of the off-line instrumental activation analysis. This is possible, because phosphorus is not a gamma-ray emitter.

Phosphorus-31 is the only isotope in natural phosphorus (100\% abundance) and it has a low cross-section for thermal neutrons (0.19 barns) (30). Accordingly, the ${ }^{32} \mathrm{p}$ gammaray Iines due to capture of thermal neutrons in ${ }^{31} \mathrm{P}$ are expected to appear with low intensities.

For standardization purposes the reference samples have been prepared by mixing $\left(\mathrm{NH}_{4}\right)_{2} \mathrm{HPO}_{4}$ and $\mathrm{Al}_{2} \mathrm{O}_{3}$ with $\mathrm{P}$ content of $0.0,5.92,11.84,17.76$ and $29.6 \%$ to be used in case of phosphorus determination in industrial waters using $\mathrm{Al}_{2} \mathrm{O}_{3}$ filters.

A weight of $100 \mathrm{gm}$ of each sample in a powder form was used. The time for collecting the spectrum for each sample was 40000 seconds. An example of the prompt gamma-ray spectrum obtained from thermal neutron capture in ammonium phosphate mixed with $\mathrm{Al}_{2} \mathrm{O}_{3}$ of $17.76 \% \mathrm{P}$ is presented in figs. 7.a, 7.b, 7.d and 7.e. More than 150 gamma-ray lines appeared in the energy range of 500 to $9000 \mathrm{keV}$. In addition to the background lines, the phosphorus lines, as well as the aluminium and nitrogen lines could be observed. More than 20 gamma-ray Iines of phosphorus appeared. The most intense and well resolved lines at $2154,3523,4672$ and $6785 \mathrm{keV}$ were used (21-23) to construct the calibration curves as shown in figs. 8.a, 8.b, 8. C and 8.d.

Similar calibration studies have been done using mixtures of $\mathrm{CaCO}_{3}$ and $\mathrm{Ca}_{3}\left(\mathrm{PO}_{4}\right)_{2}$ with phosphorus concentrations, $0.0,6.81$, $8.85,10.75,12.80$ and $19.98 \%$, in case of determination of phosphorus in lime samples. The first and the last samples were prepared at our laboratory and the other four samples were submitted by (Wasserchemie - KFK) (32). 
A weight of $50 \mathrm{gm}$ of each sample in powder form was used and the time for collecting the spectrum was 40000 seconds.

Figs. 9.a, 9.b, 9.c and 9.d, show an example of prompt gammaray spectrum from thermal neutron capture in one of the calcium phosphate samples in the energy region of 500 to $9000 \mathrm{keV}$. Once again a complex spectrum appears, containing more than 125 gamma-ray lines. In addition to the background lines, the phosphorus and some of calcium lines could be noticed. The well resolved and intense lines of phosphorus at 3523 and $4672 \mathrm{keV}$ were used to establish the calibration curves at the concentration values mentioned above, as shown in Eigs. 10.a and 10.b.

The phosphorus concentration values in two calcium phosphate samples (lime samples) submitted by Wasserchemie laboratories, have been determined using the calibration curves mentioned above, under the same experimental conditions. The results obtained are presented in Table 3. The table shows also a comparison between our results and the values reviewed by the Wasserchemie reports (32). We note that there is fair agreement between the results of the present work and the reported values (32) within the limits of the statistical errors which ranging between 5 to $10 \%$ depending on the intensity of the gamma-ray lines used.

\section{CONCLUSIONS}

A PGNAA facility using the 252-Cf neutron sources has been designed, installed and calibrated at IRCH - KFK. It is a tool well suited for elemental analysis of complex samples. The technique has the ability to simultaneously measure the elements occuring in large concentrations which are difficult to measure by the instrumental techniques.

The agreement between the results presented in this work and previously reported data, especially in the case of boron 
determination, indicate that the PGNAA is an accurate technique for measuring the small quantities of this element in its compounds.

Taking into consideration the prompt gamma-ray spectra measured and the calibration curves obtained for $\mathrm{B}, \mathrm{Cl}$ and $P$, a remarkable improvement of the detection limits can be obtained $(0.005$ to $30 \%)$.

Using a larger gamma-ray detector and stronger neutron source, the sensitivity of this technique can be improved especially in the case of low cross-section elements such as $P$, which has a relatively high statistical error in our results.

It is thus shown that prompt gamma-ray techniques using 252-Cf isotopic neutron. sources represent. among other analytical tools an appreciably useful estimation method.

\section{ACKNOWLEDGEMENTS}

The authors are extremely grateful for the very active encouragement of Prof. Dr. H. J. Ache, the Chief of the IRCH-KFK. The cooperation of the IRCH work-shop staff in setting up the mechanical parts of the facility is appreciated.

One of the authors (A. M. HASSAN) wishes to thank the authorities of the International Buiro of Jilich for their financial support through the German-Egyptian bilateral agreement in the period when this work was done, and $\mathrm{AEE}$ of Egypt for kindly granting the necessary leave of absence. 


\section{REFERENCES}

1) Ian P. Matthews and Nicholas M. Sprou

Multielemental Analysis of Bulk Matrices by Measurement of Prompt and Delay $\gamma$-Rays as well as Cyclic Activation Using Isotopic Neutron Sources. Int. J.Appl. Radiat. Isot. Vol 33 pp. 61 to 68 (1982).

2) A. M. Hassan, A. El. Kady and B. El. Ezaby. A Prompt Gamma-Ray System for Elemental Analysis of Complex Samples.

Nucl. Inst. and Meth. 192, 595 - 601 (1982).

3) Michael D. Glascock

Practical Applications of Neutron-Capture Reactions and Prompt Gamma-Rays.

Paper Presented at 4 th $(n, \gamma)$ Int. Symp. Grenoble 7 - 11 sept. (1981).

4) D. I. Anderson, W. H. Zoller, G. E. Gordon and

W. B. Walters.

Neutron-Capture Prompt Gamma-Ray spectrometry as a Quantitative Analytical Method.

Paper Presented at. 4 th $(n, \gamma)$ Int. Symp. Grenoble 7 - 11 Sept. (1981).

5) D. L. Anderson, M. P. Failey, W. H. Zoller,

W. B. Walters, G. E. Gordon and R. M. Iindstrom.

Facility for Nondestructive Analysis for Major and

Trace Elements Using Neutron-Capture Gamma-Ray Spectrometry.

J. of Radioanal. Chem. Vol 63, No. 1,97-119 (1981).

6) M. P. Failey, D. L. Anderson, W. H. Zoller, and

G. E. Gordon.

Neutron Capture Prompt Gamma-Ray Activation Analysis for Multielement Determination in Complex Samples.

Anal. Chem. Vol. 51, No. 13, 2209, (1979).

7) R. C. Greenwood.

Practical Applications of Neutron Capture Gamma-Rays. Proceedings of the 3rd Int. Symp. on Neutron Capture Gamma-Ray Spectroscopy and Related Topics.

BNL, Upton, New York, Sept. 18 - 22, 441, (1978).

8) D. L. Anderson, M. P. Failey, W. H. Zoller and

G. E. Gordon.

Neutron-Capture Prompt Gamma-Ray Activation Analysis: Multielement Measurement on Various Materials. Proc. of the 3rd Int. Symp. on $(n, y)$ Spectroscopy and Rel. Topics.

BNI, Upton, New York, Sept. $18-22$, 546, (1978). 
9) B. R. S. Pecequilo and A. A. Suarez

Fuel Material Analysis Using Radioactive Thermal

Neutron Capture. Proc. of the 3rd Int. Symp. on

$(n, \gamma)$ Spectroscopy and Rel. Topics.

BNL, Upton, New York, Sept. $18-22,710$, (1978).

10) M. Sohrabpour, A. A. Soltanieh, V. Zarifian.

In Situ Capture Gamma-Analysis of Large Mineral

Samples. Proc. of the 3 rd Int. Symp. on $(n, \gamma)$

Spectroscopy and Related Topics.

Upton, New York, Sept. $18-22,760$, (1978).

11) A. M. Hassan, M. R. Wormald and C. G. Clayton.

Simataneous Multi-element Analysis of Coal by Neutron

Interaction Techniques.

The 5th Symp. on Recent Development in Activation

Analysis. Oxford U. K. (1978).

12) M. R. Ghavi and C. O. Cogburn

Coal Analysis by Cf-252 Induced Capture-Gamma-Spectrometry. Proc. of the 3rd Int. Conf. on Nucl. Meth. in

Environmental and Energy Research. Columbia, Missouri, Oct. $10-13,403,(1977)$.

13) Larry R. Lapides, Jacob I. Trombika and Dal. H. Jensen. In Situ Elemental Analysis Using Neutron Capture GammaRay Spectroscopy.

Nucl. Instr. and Meth. 193, 353 - 357 (1982).

14) A. M. Hassan, A. Habib, A. El. Kady and I. Hamouda. Use of Radiative Capture Technique for Multielement Analysis of Domestic Hematite Sample.

Radiochem. Radioanal. Letters 49/5/323 - 340 (1981).

15) J. A. Lubkwitz, M. Heurtebise and H. Buenafama.

Recent Analytical Àpplications of Neutron Capture

Gamma-Ray Spectroscopy from IDEA to Appl., Some Selec-

ted Nucl. Techniques in Res. and Dev. Proc. of an Ad-

visory Group-Meeting, San José Costa Rica, 9-13 May 1977,

IAEA Vienna, $125-149$ (1978).

16) Y. Kusaka and H. Tsuji

Non-Destructive Determination of Chlorine in Organic

Compounds by Neutron Capture Gamma-Ray Measurement,

Using an Isotopic Neutron Source.

J. Radioanal. Chem. 5, $359-367$ (1970) .

17) T. Chris Clark, Robin P. Gardner and Kuruvilla Verghese.

A Monte Carlo Model for In-Situ Prompt Gamma-Ray Ana-

lysis Probes

Nucl. Instr. and Methods 193, 365 - 370 (1982). 
18) T. Lukander and S. Uusitalo

On Line Neutron Capture Gamma-Ray Analysis with a Ge Detector Proc. of the 3rd Int. Symp. on $(n, \gamma)$ and Related Topics.

BNL, Upton New York, Sept. $18-22,681$, (1978).

19) G. Subrahmanian, G. Venkatraman and U. Madhvanath. Radiation Protection Aspects in the Use of 252-Cf Sources.Proc. Ed. Seminar, Karlsruhe 14-18 April (1975) IAEA-SR-3/8, Vienna (1976).

20) S. M. Lombard and T. I. Isenhour. Determination of Samarium and Gadolinium in Rare Earth Ores by Neutron Capture Gamma-Ray Activation Analysis.

Anal. Chem. Vol. 41, No. 8, July (1969).

21) F. E. Senftle, H. D. Moore, D. B. Leep, A. El-Kady and D. Duffy.

Analytical Sensitivities and Energies of Thermal

Neutron Capture Gamma-Rays II.

Nuc1. Instr. and Meth. 93, 425 - 459 (1971).

22) D. Duffey, A. El-Kady and F. E. Senftle.

Analytical Sensitivities and Energies of Thermal Neutron Capture Gamma-Rays I.

Nucl. Instr. and Meth. 80, 149 - 171 (1970).

23) N. C. Rasmussen, Y. Hukai, T. Inouye and V. Oxphan. Thermal Neutron Capture Gamma-Ray Spectra of the Elements, Report AFCRL-69-0071 / Mass. Inst. Tech. Cambridge, Mass, U. S. Air Force Camb. Res. Lab. Bedford Mass. Jan. (1969).

24) H. B. Sales and C. C. Dantas.

Determination of Boron in Water solution by an Indirect Neutron Activation Technique.

Radiochem. Radioanal. Letters 50/2/105 - 112 (1981).

25) M. A. Lone, D. C. Santry and W. M. Inglis.

MeV Neutron Production from Thermal. Neutrons in Li and B Compounds.

Nucl. Instr. and Meth. 174, 521 - 529 (1980).

26) Edward T. Jurney.

Application of the Thermal $(n, \gamma)$ Reaction to Elemental Analysis. Proc. of the $3 r d$ Int. Symp. on $(n, \gamma)$

Spectroscopy and Related Topics

BNL, Upton, New York, Sept. $18-22,461$, (1978). 
27) Ernest S. Gladney, Edward T. Jurney and David B. Curtis. Nondestructive Determination of Boron and Cadmium in Enviromental Materials by Thermal Neutron-Prompt $\gamma$-Ray spectrometry.

Anal. Chem. Vol. 48, No. 14, 2139 - 2142, Dec. 1976.

28) R. Henkelmann, and H. J. Born.

Analytical Use of Neutron Capture Gamma-Rays

J. of Rad. Anal. Chem. Vol. 16, 473 - 481 (1973).

29) D. Comar, C. Crouzei, M. Chasteland, R. Riviere and C. Kellershohn.

The Use of Neutron Capture Gamma Radiation for the Analysis of Biological Samples.

Nucl. Appl. Vol. 6, 344 - 351, April (1969).

30) R. C. Greenwood and J. H. Reed

Prompt Gamma-Rays from Radiative Capture of Thermal Neutrons. Vol. 1 and 2 .

IITRI - 1193 - 53 - TID. 4500 Chicago, Illinois 60616 Oct. 14, (1965).

31) Verkaufsinformation der Schott-Ruhrglas GmbH (SR $31 / 74)$, (1982).

32) D, Donnert, Private Communication 
List of Tables

Table 1: Gamma-ray energies used for energy calibration $(21-23)$

Table 2: A comparison between the boron concentration values in glass materials obtained by the PGNAA technique and the industrial certified values

Table 3: A comparison between the phosphorus concentration values in calcium phosphate samples, obtained by the PGNAA technique and the reported values 
Table 1: Gammy-Ray Energies Used for Energy Calibration $(21-23)$.

\begin{tabular}{|c|c|}
\hline Source ${ }^{+1}$ & $\mathrm{E} \gamma \mathrm{keV}$ \\
\hline Annihillation & 511.0 \\
\hline $\mathrm{H}^{\prime \prime}$ & 1201.1 \\
\hline $\mathrm{H}^{\prime}$ & 1712.1 \\
\hline $\mathrm{H}$ & 2223.1 \\
\hline $\mathrm{Fe}$ & 3267.8 \\
\hline $\mathrm{C}$ & 3693.9 \\
\hline $\mathrm{Fe}$ & 4218.8 \\
\hline $\mathrm{Fe} "$ & 4898.5 \\
\hline $\mathrm{C}$ & 4945.2 \\
\hline $\mathrm{Fe} "$ & 4996.5 \\
\hline $\mathrm{Fe}^{\prime}$ & 5409.5 \\
\hline $\mathrm{Fe}^{\prime}$ & 5507.5 \\
\hline $\mathrm{Fe}$ & 5920.5 \\
\hline $\mathrm{Fe}$ & 6018.5 \\
\hline $\mathrm{Pb} "$ & 6345.7 \\
\hline Fèl & 6609.6 \\
\hline $\mathrm{Fe} "$ & 6623.6 \\
\hline $\mathrm{Pb} \mathrm{b}^{\prime}$ & 6856.7 \\
\hline $\mathrm{Fe}^{\prime}$ & 7120.6 \\
\hline $\mathrm{Fe}^{\prime}$ & 7134.6 \\
\hline $\mathrm{Pb}$ & 7367.7 \\
\hline $\mathrm{Fe}$ & 7631.6 \\
\hline $\mathrm{Fe}$ & 7645.6 \\
\hline $\mathrm{Fe} "$ & 8276.4 \\
\hline $\mathrm{Fe}^{\prime}$ & 8787.4 \\
\hline
\end{tabular}

+) The single and double escape peaks are labelled by (') and ("). 
Table 2: A Comparison Between the Boron

Concentration Values in Glass Materials

Obtained by The PGNAA Technique and the

Industrial Certified Values.

$\begin{array}{lll}\text { Sample } & \begin{array}{l}\text { Certified } \\ \text { Values } \\ (\text { Bo(Ref.31)) }\end{array} & \text { Present Work }+) \\ \text { - Pyrex Borosilicate } & 3.913 & 4.120 \\ \text { Glass } & & \\ \text { - Duran-50 Glass } & 4.037 & 4.105 \\ \text { - G-20 Glass } & 2.981 & 3.025 \\ & & \\ \text { - Raschig Rings } & & 3.304 \\ \text { Glass } & & \end{array}$

+ The statistical error was $\sim 5 \%$. 
Table 3: A Comparison Between the Phosphorus Concentration Values in Calcium Phosphate Samples, Obtained by the PGNAA Technique and The Reported Values.

Sample

Reported

Present

Values $(\mathrm{P} \%) \quad$ Work $(\mathrm{P} \%)^{+)}$

(Ref. 32)

- Berlin $4-5 t-1$

12.03

12.50

- Berlin 4 - St - 2

9.37

9.51

+) The statistical error was ranging from 5 to $10 \%$. 
Figure Captions:

Fig. 1-a. Overall sketch of the Prompt Gamma Neutron Activation Analysis (PGNAA) facility using the 252-CE neutron sources.

Fig. 1-b. Top view of the base section of the (PGNAA) facility.

Fig. 1-c. Plan view of the sample and the 252-Cf sources holders.

Fig. 1-d. A vertical cross-section of the gamma-ray collimator.

Fig. 2. Photographs. of the (PGNAA) facility

a- Side view

b- Sample position

c- Detector position

d- Overall view.

Fig. 3. A portion of the prompt gamma-ray spectra, resulting from thermal neutron irradiation of $\left(\mathrm{H}_{3} \mathrm{BO}_{3}+\mathrm{H}_{2} \mathrm{O}\right)$ samples showing the Doppler shifted B gamma-ray peaks emitted for different concentration percentages.

Fig. 4-a. Calibration curve for boron determination up to 1.0 using $\left(\mathrm{H}_{3} \mathrm{BO}_{3}\right.$ in $\left.\mathrm{H}_{2} \mathrm{O}\right) \mathrm{T}=4000$ seconds.

Fig. 4-b. Calibration curve for boron determination up to 0.1 : using (Boron Carbide and seasand). $\mathrm{T}=4000$ seconds. 
Fig. 5-a. An example of prompt gamma-ray spectra from thermal neutron Capture in $\mathrm{NaCl}$ standard reference material dissolved in $\mathrm{H}_{2} \mathrm{O}\{100 \mathrm{ml}$. $10.0 \% \mathrm{cl}\}$. The spectra were recorded in a singles mode with $85 \mathrm{~cm}^{3} \mathrm{Ge}(\mathrm{Li})$ detector using the 252-Cf based PGNAA facility. The irradiation time was 10000 seconds. The energies in keV could be obtained for some of the prominent line features. The single and double escape peaks are labelled by (') and (") respectively. The energy range (750 - $2240 \mathrm{keV})$.

Fig. 5-b. Cont. The energy range (2240 - $4550 \mathrm{keV})$

Fig. 5-c. Cont. The energy range (4550 - $6800 \mathrm{keV})$

Fig. 5-d. Cont. The energy range (6800 - $9000 \mathrm{keV})$

Fig. 6-a. Calibration curve for chlorine determination in ( $\mathrm{NaCl}$ ) using the gamma-ray line at $789 \mathrm{keV}$, $T=40000$ seconds.

Fig. 6-b. Calibration curve for chlorine determination in $\mathrm{NaCl}$ using the gamma-ray line at $1185 \mathrm{keV}$, $\mathrm{T}=40000$ seconds.

Fig. 6-c. Calibration curve for chlorine determination in $\mathrm{NaCl}$ using the gamma-ray line at $2884 \mathrm{keV}$, $\mathrm{T}=40000$ seconds.

Fig. 6-d. Calibration curve for chlorine determination in $\mathrm{NaCl}$ using the gamma-ray line at $5715 \mathrm{keV}$, $T=40000$ seconds.

Fig. 6-e. Calibration curve for chlorine determination in $\mathrm{NaCl}$ using the gamma-ray line at $7790 \mathrm{keV}$, $\mathrm{T}=40000$ seconds. 
Fig. 6-f. Calibration curve for chlorine determination in NaCl using the gamma-ray line at $8579 \mathrm{keV}$, $T=40000$ seconds.

Fig. 7-a. An example of prompt gamma-ray spectra from thermal neutron capture in ammonium phosphate and aluminium oxide standard reference material $\{100 \mathrm{gm}, 17.76 \% \mathrm{P}\}$ in the energy range $(750-2240 \mathrm{keV})$. The spectra were recorded in a singles mode with $85 \mathrm{~cm}^{3} \mathrm{Ge}(\mathrm{Li})$ detector using 252-Cf based (PGNAA) facility. The irradiation time was 40000 seconds. The energies in $\mathrm{keV}$ could be obtained for some of the prominent line features. The single and double escape peaks are labelled by (') and (") respectively.

Fig. 7-b. Cont. The energy range $(2240-4550 \mathrm{keV})$

Fig. 7-c. Cont. The energy range $(4550-6800 \mathrm{keV})$

Fig. 7-d. Cont. The energy range (6800 - $9000 \mathrm{keV})$

Fig. 8-a. Calibration curve for phosphorus determination in ammoniumphosphate + aluminium oxide standard material). Using the gamma-ray line at $2154 \mathrm{keV})$. $T=40000$ seconds.

Fig. 8-b. Calibration curve for phosphorus determination In ammoniumphosphate + aluminium oxide standard material\}.Using the gamma-ray line at $3523 \mathrm{keV} . \mathrm{T}=40000$ seconds.

Fig. 8-c. Calibration curve for phosphorus determination in ammoniumphosphate + aluminium oxide standard material\}. Using the gamma-ray line at $4672 \mathrm{keV} . \mathrm{T}=40000$ seconds. 
Fig. 8-d. Calibration curve for phosphorus determination \{in ammoniumphosphate + aluminium oxide standard material\}. Using the gamma-ray line at $6785 \mathrm{keV} . \mathrm{T}=40000$ seconds.

Fig. 9-a. An example of prompt gamma-ray spectra from thermal neutron capture in calcium phosphate reference material (50 $\mathrm{gm}, 9.37 \% \mathrm{P})$ in the energy range $(750-2240, \mathrm{kev})$.

The spectra were recorded in a singles mode with $85 \mathrm{~cm}^{3} \mathrm{Ge}(\mathrm{Li})$ detector using 252-Cf based (PGNAA) facility. The irradiation time was 40000 seconds. The energies in $\mathrm{keV}$ could be obtained for some of the single and double escape peaks are labelled by (') and (") respectively.

Fig. 9-b. Cont. The energy range (2240 - $4550 \mathrm{keV})$

Fig. 9-c. Cont. The energy range (4550 - $6800 \mathrm{keV})$

Fig. 9-d. Cont. The energy range (6800 - $9000 \mathrm{keV})$

Fig.10-a. Calibration curve for phosphorus determination in (Calcium phosphate samples). Using the gammaray line at $3523 \mathrm{keV} . \mathrm{T}=40000$ seconds.

Fig.10-b. Calibration curve for phosphorus determination in (Calcium phosphate samples). Using the gammaray line at $4672 \mathrm{keV} . \mathrm{T}=40000$ seconds. 


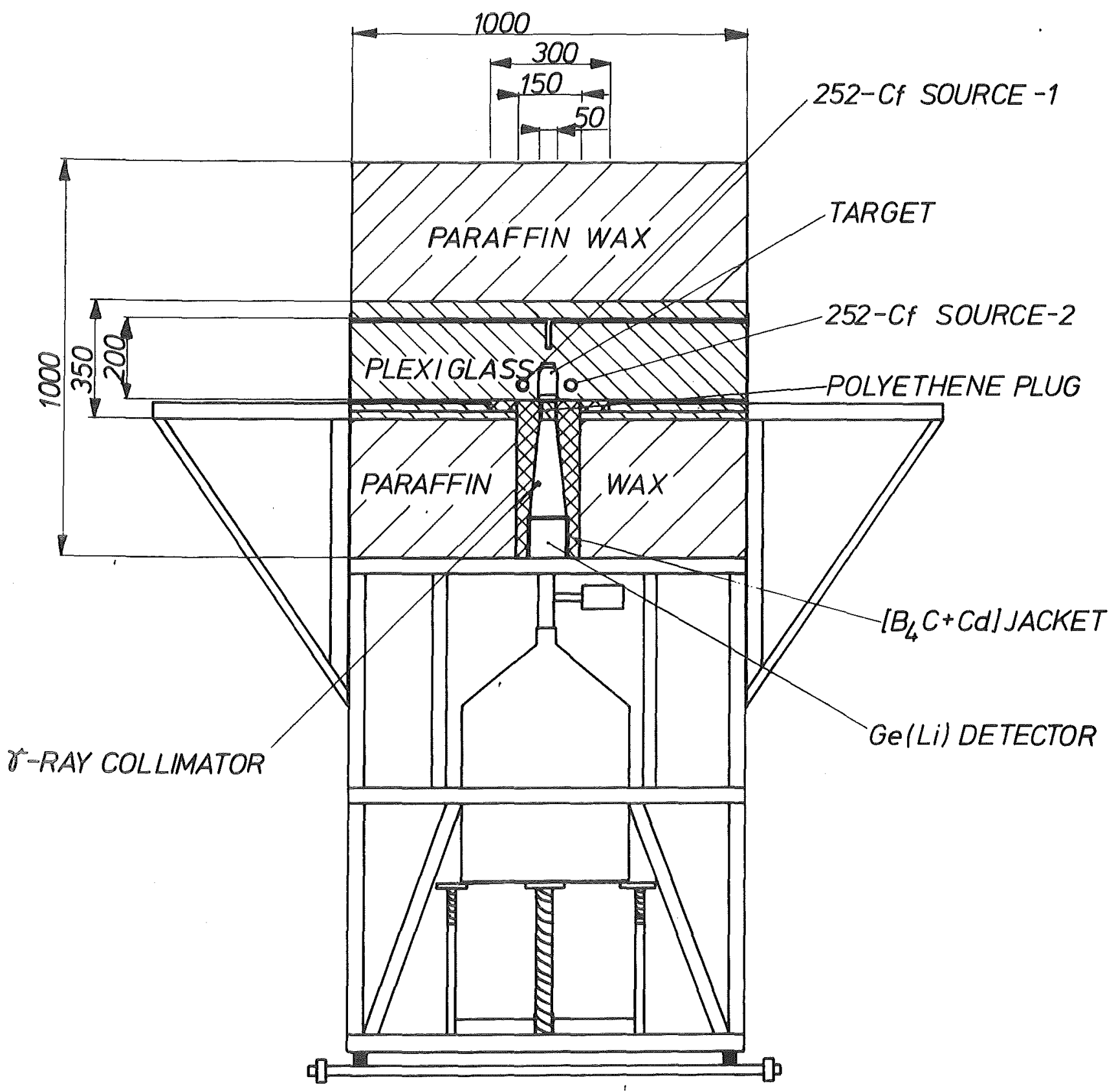

FIG 1-a. OVERALL SKETCH OF THE PROMPT GAMMA NEUTRON ACTIVATION ANALYSIS (PGNAA) FACILTYY USING THE 252-CF NEUTRON SOURCES. 


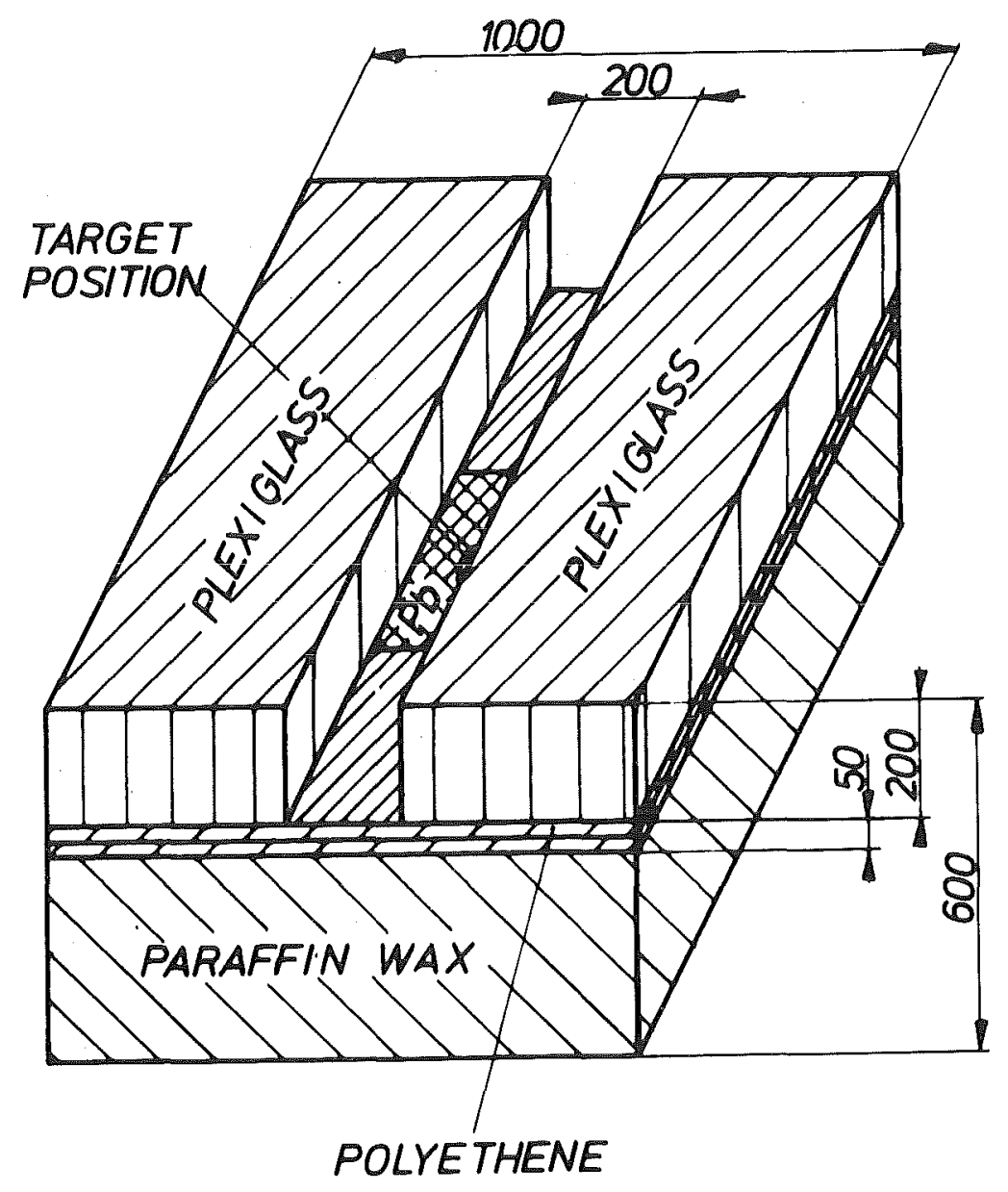

FIG. 1-b TOP VIEW OF THE BASE

SECTION OF THE (PGNAA) FACILITY

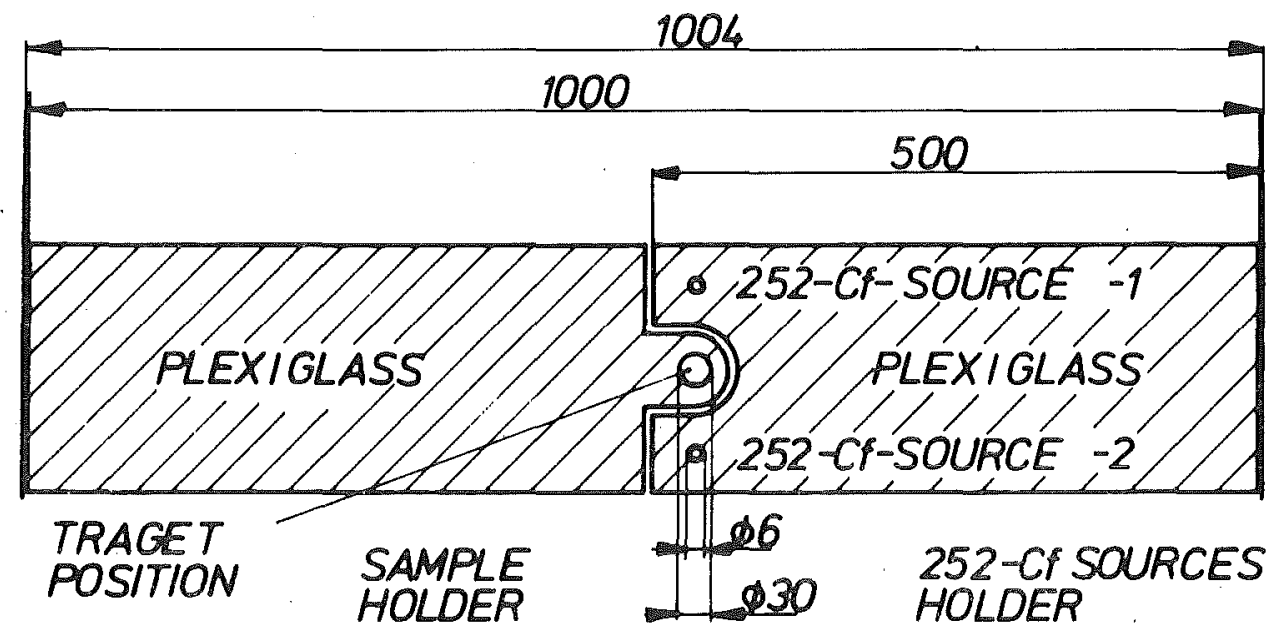

FIG.1-C PL AN VIEW OF THE SAMPLE AND THE 252-CF SOURCES HOLDERS 


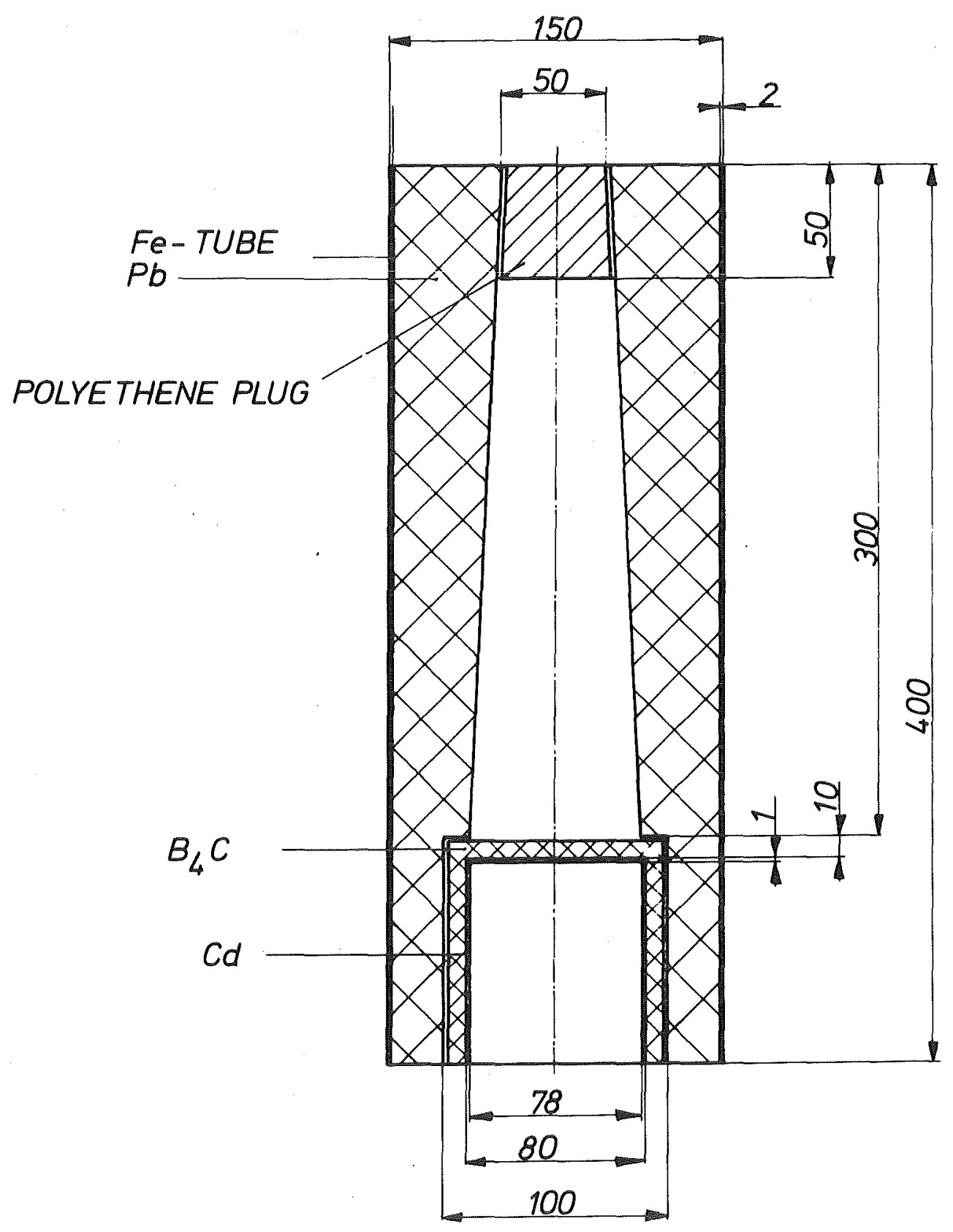

FIG.1-d. A VERTICAL CROSS- SECTION OF THE GAMMA-RAY COLLIMATOR 


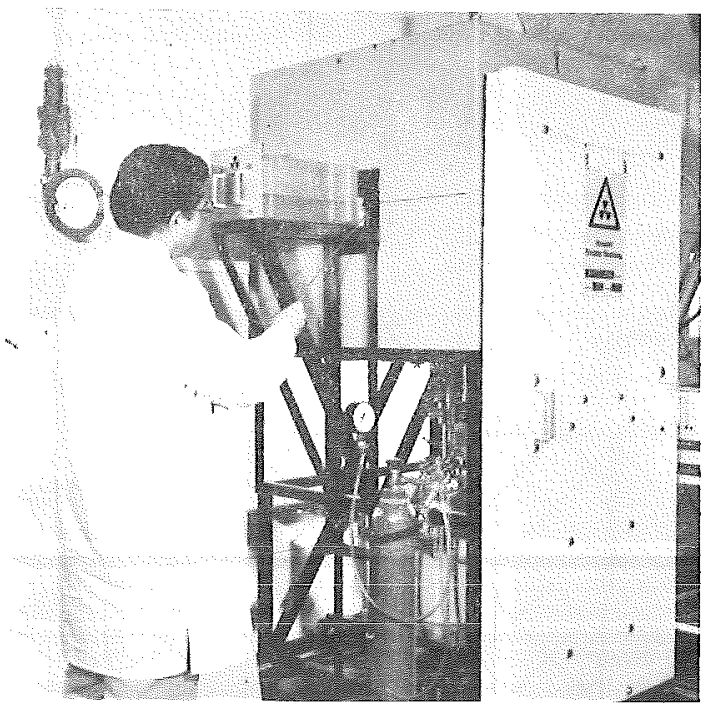

Fig. 2-a.

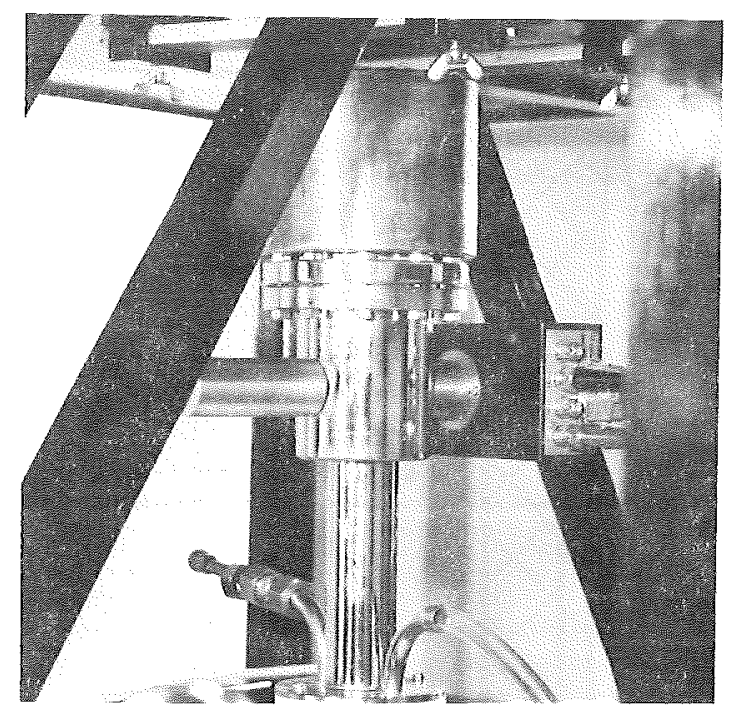

Fig. 2-c.

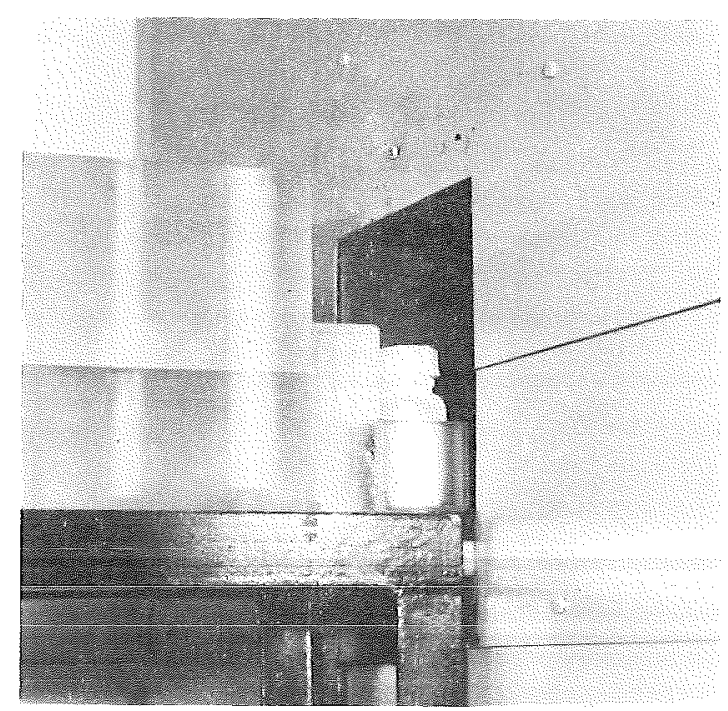

Fig. 2-b.

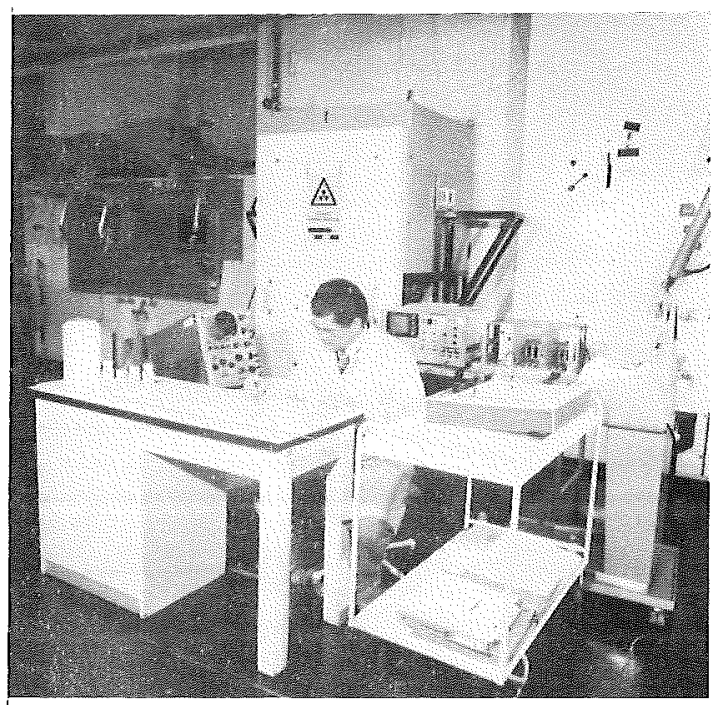

Fig. 2-d.

Fig. 2. PHOTOGRAPHS OF THE[PGNAA] FACILITY;
a. Side View.
b. Sample Position.
c. Detector Position. d.Overall View. 


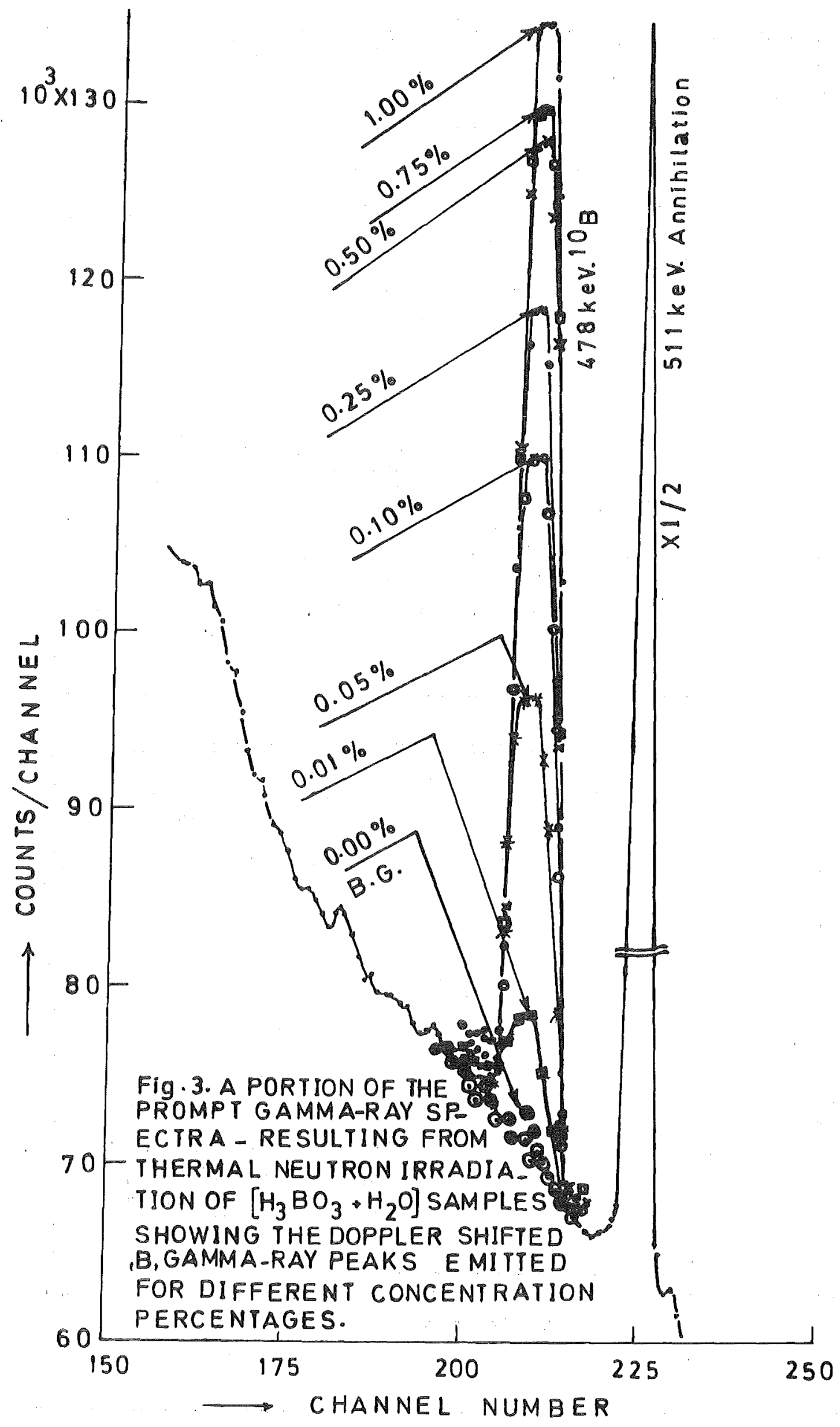



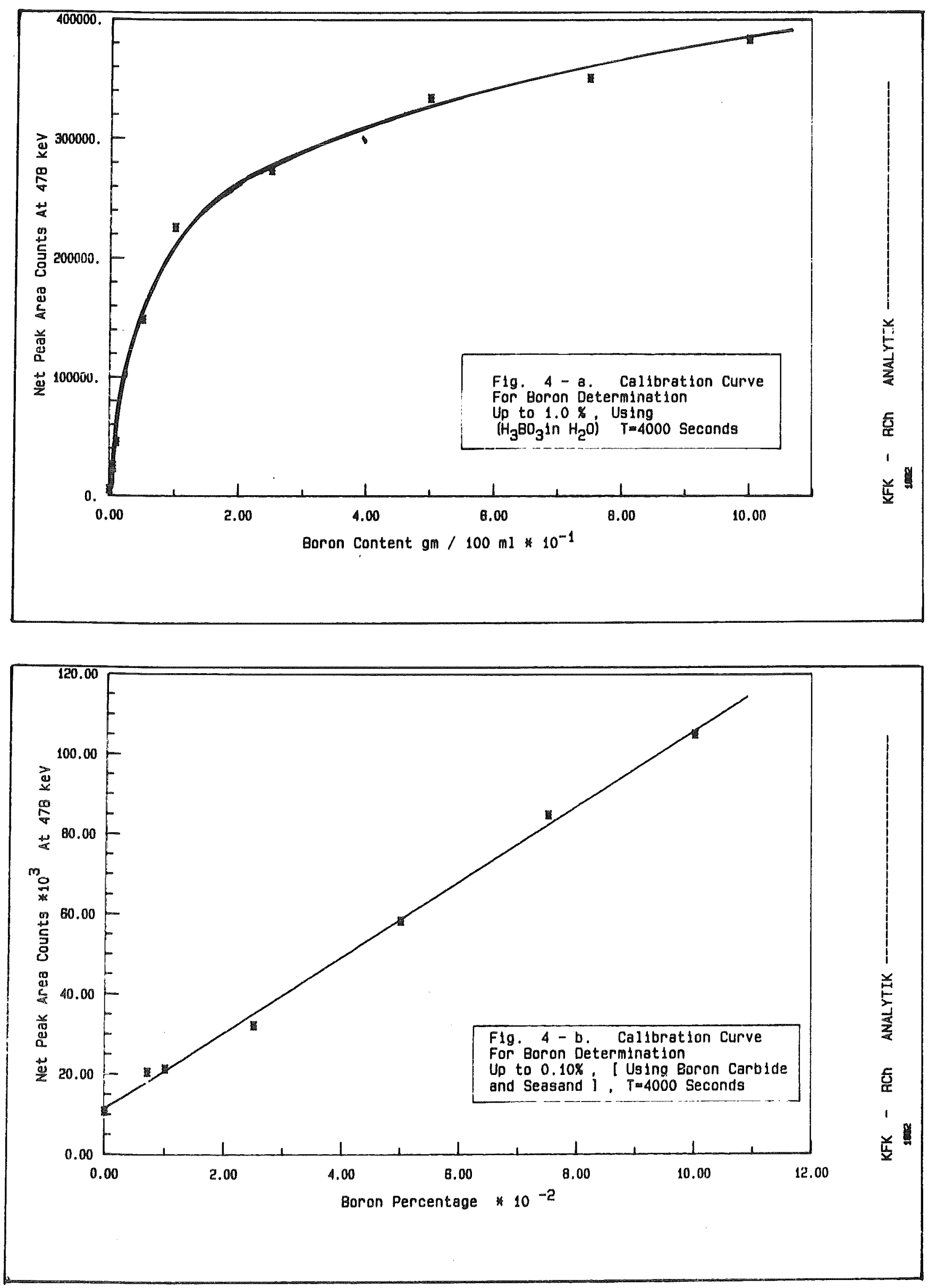


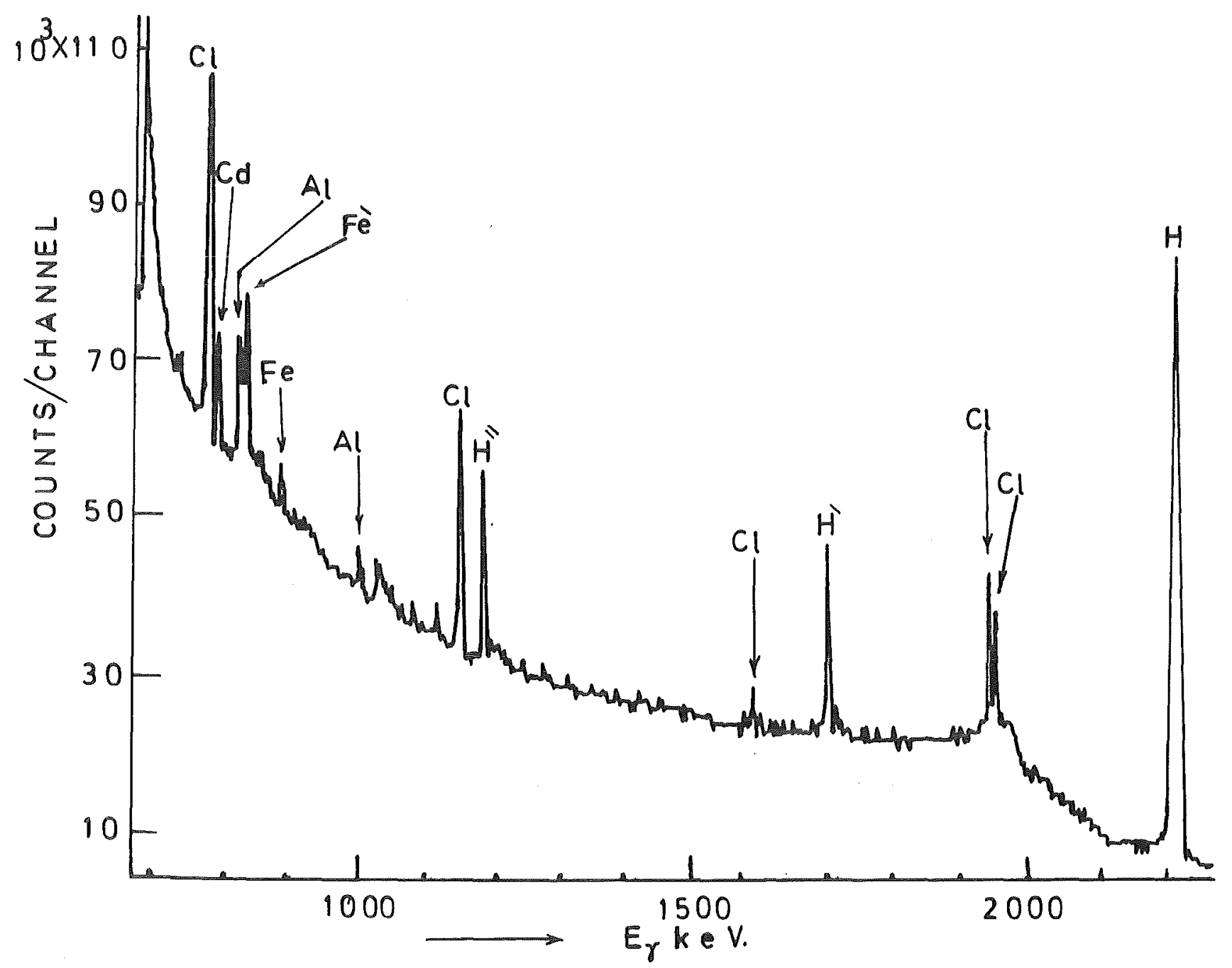

Fig. 5.2. AN EXAMPLE OF PROMPT GAMMARAY SPECTRA FROM THERMAL NEUTRON CAPTURE IN.NACI. STANDARD REFERENCE MATERIAL DISSOLVED IN H $0[100 \mathrm{ml} .10 .0 \% \mathrm{Cl}$. THE SPECTRA WERE RECORDED IN A SINGLES MODE WITH $85 \mathrm{~cm}^{3}$ Ge(Li) DETECTOR USING THE 252 .CF BASED PGNAA FACILITY. THE IRRADIATION TIME WAS 10000 SECONDS. THE ENERGIES IN KEV.COULD BE OBTAINED FOR SOME OF THE PROMINENT LINE FEATURES.THE SINGLE AND DOU BLE ESCAPE PEAKS ARE LABELLED BY( ) AND (N) RESPECTIVELY. THE ENERGY RANGE(750-2240 k eV.) 

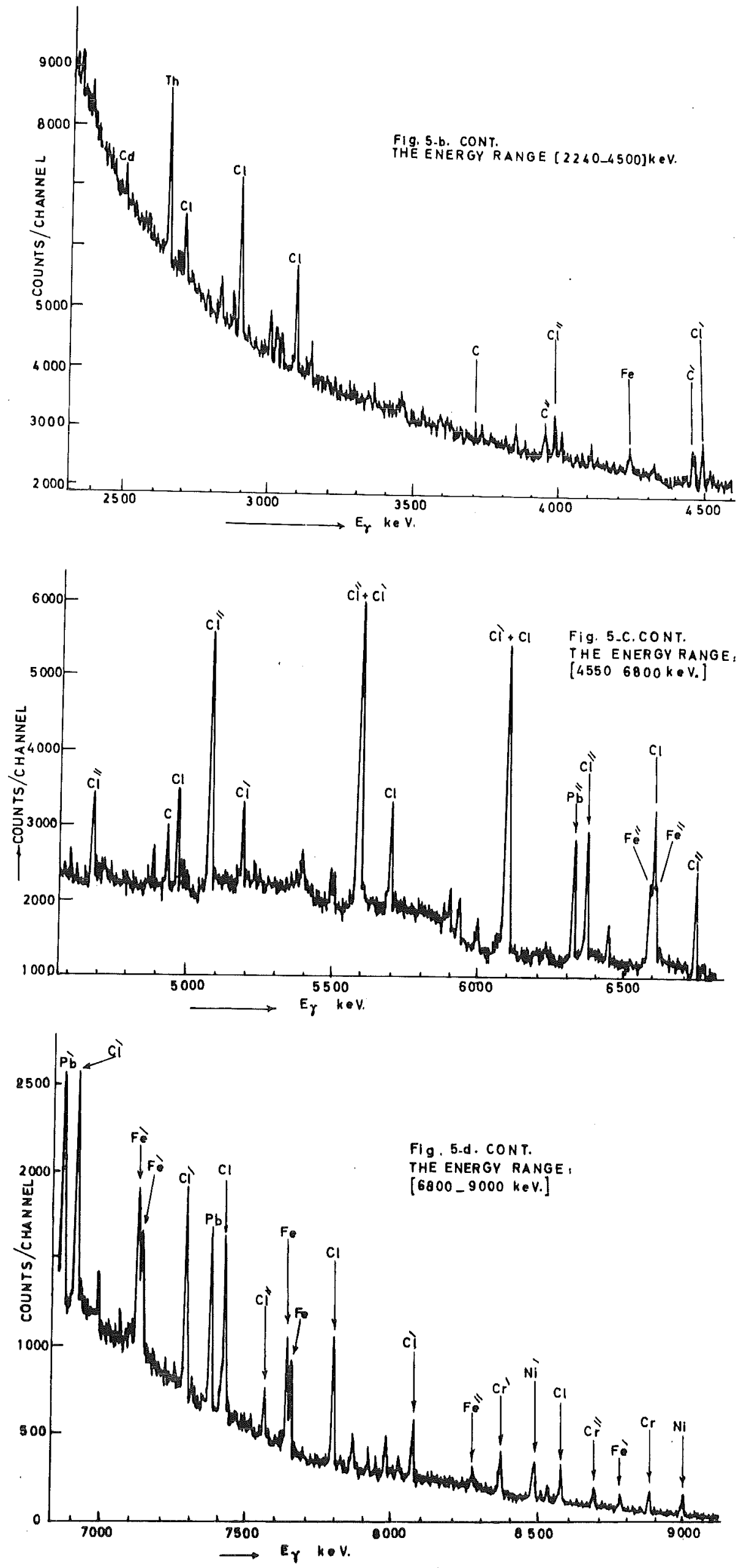

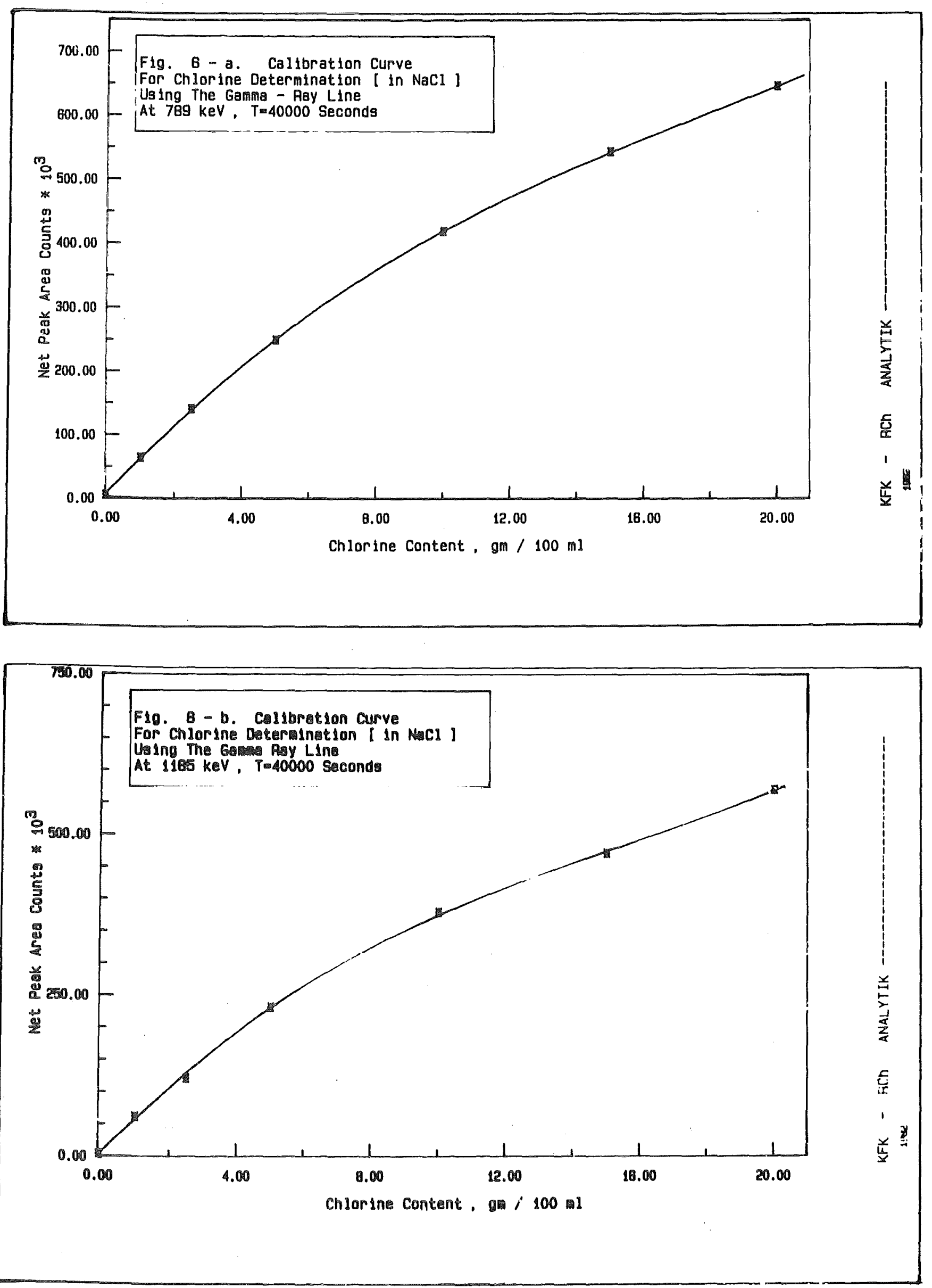

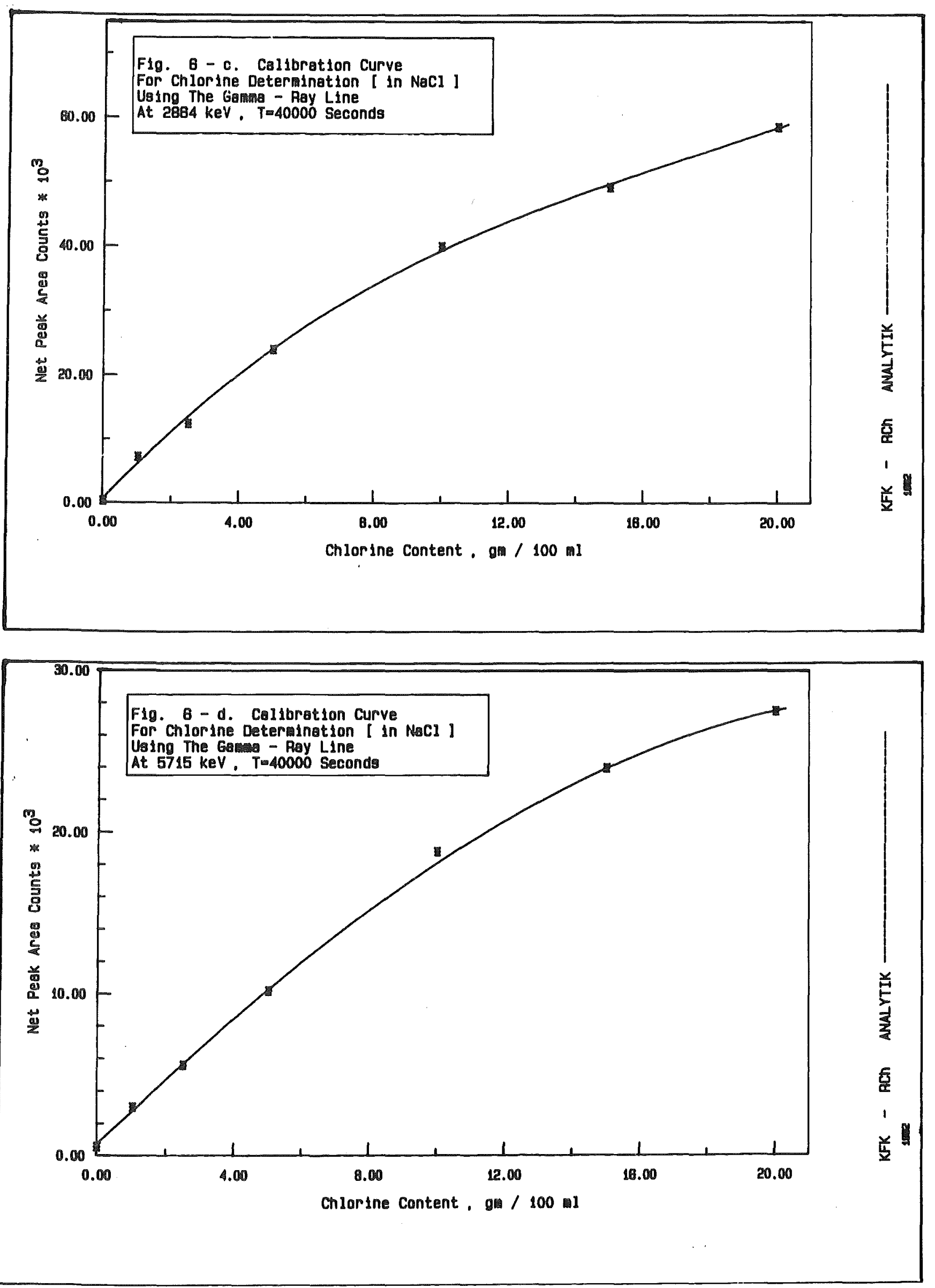

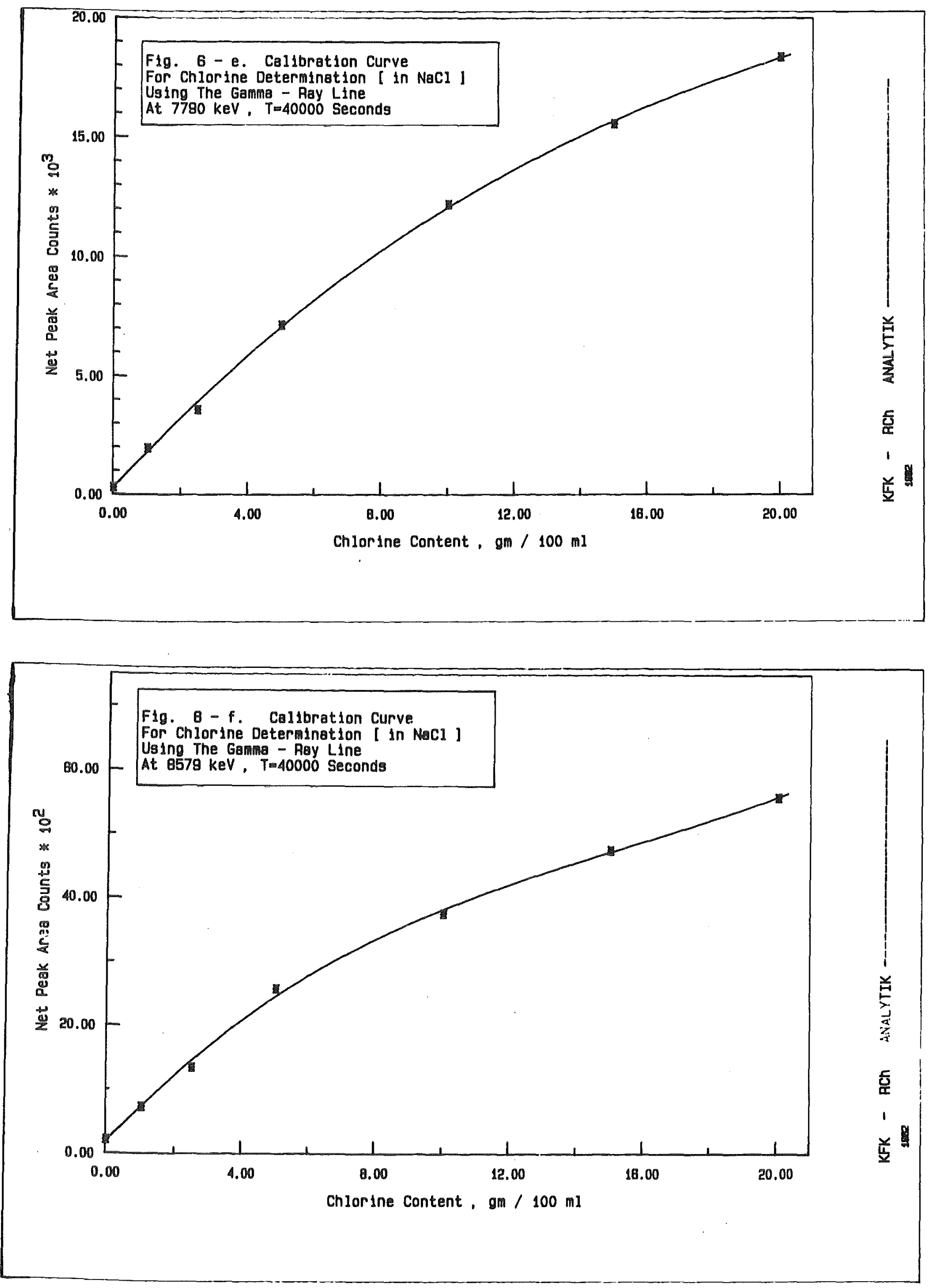


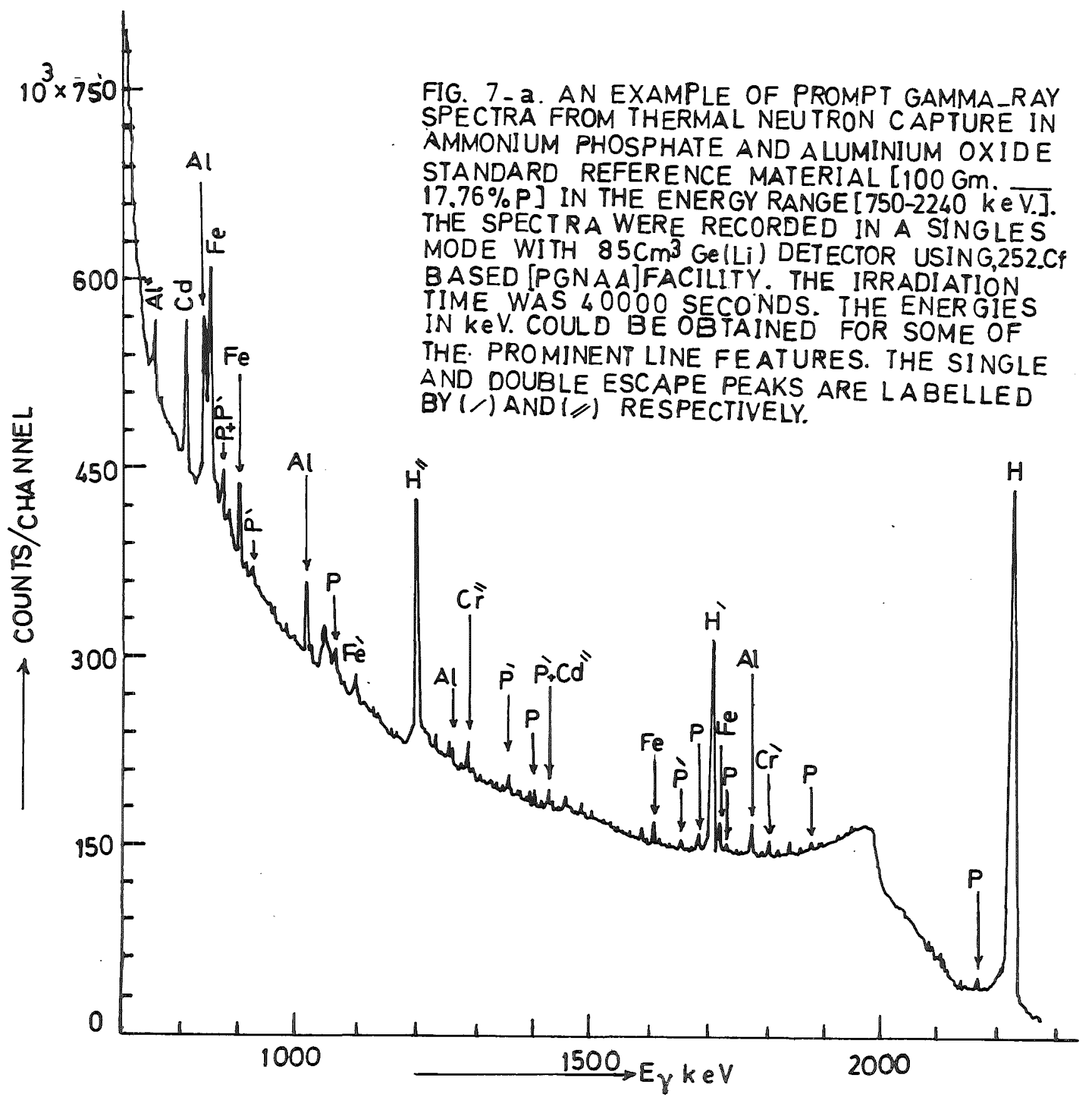


$-35-$
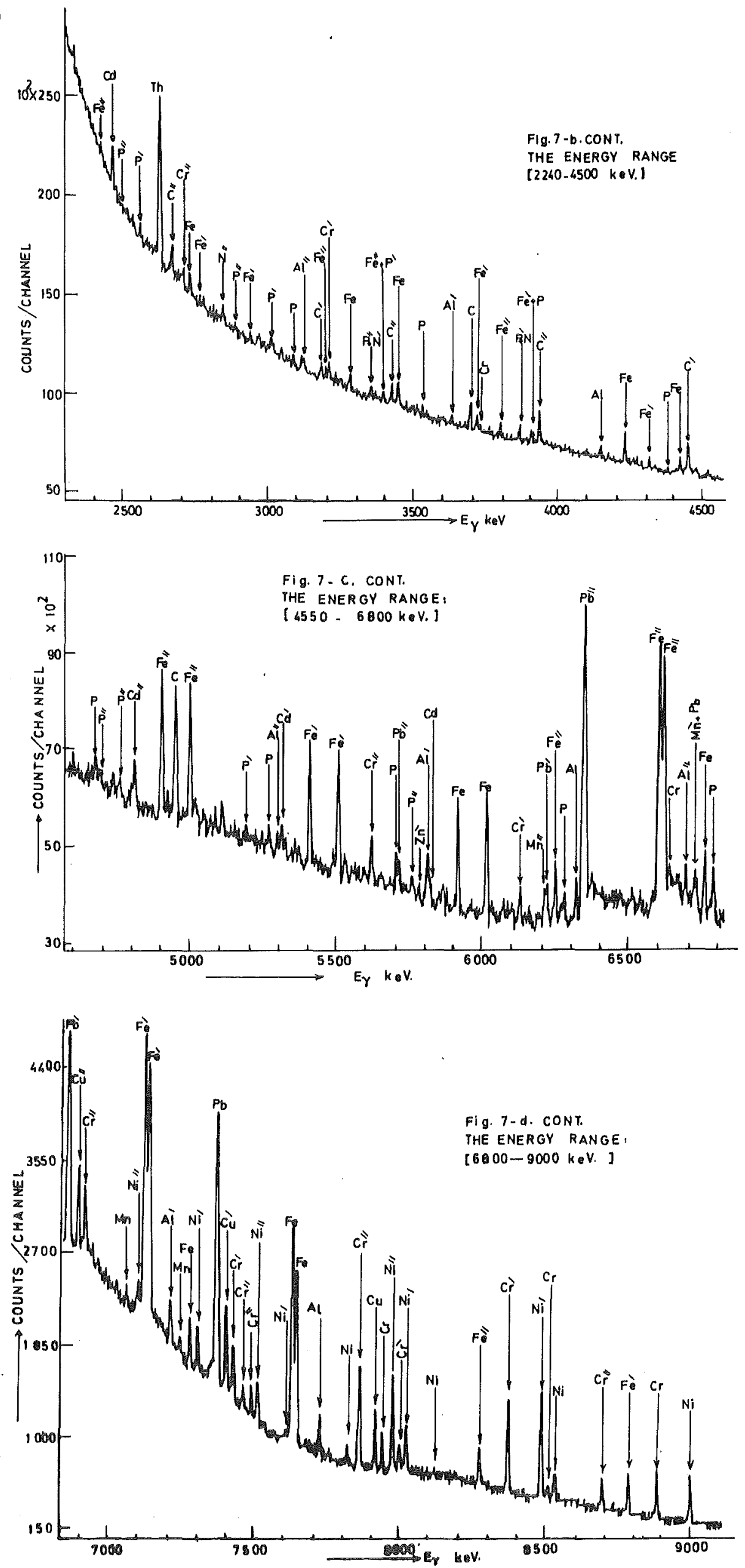

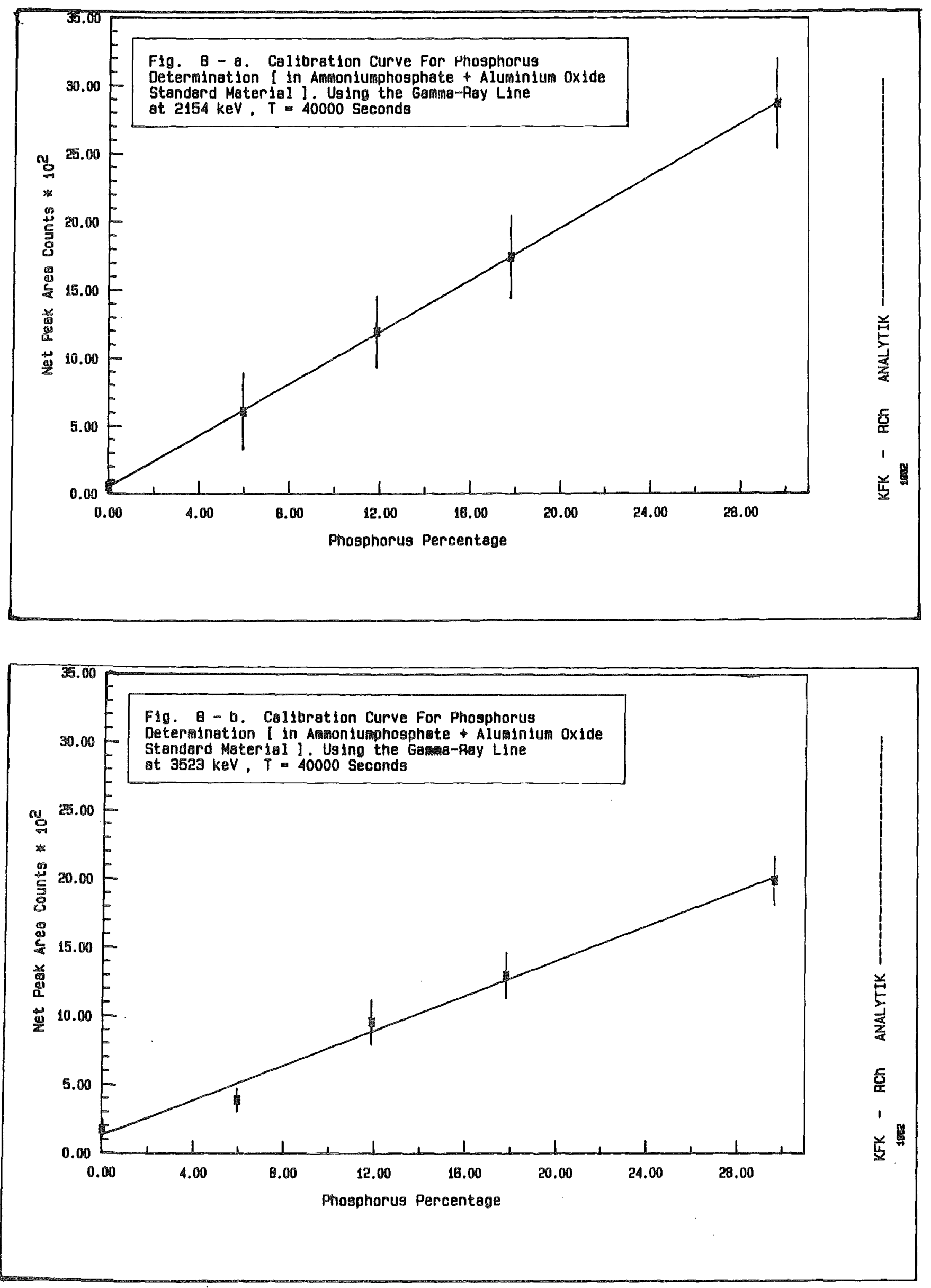

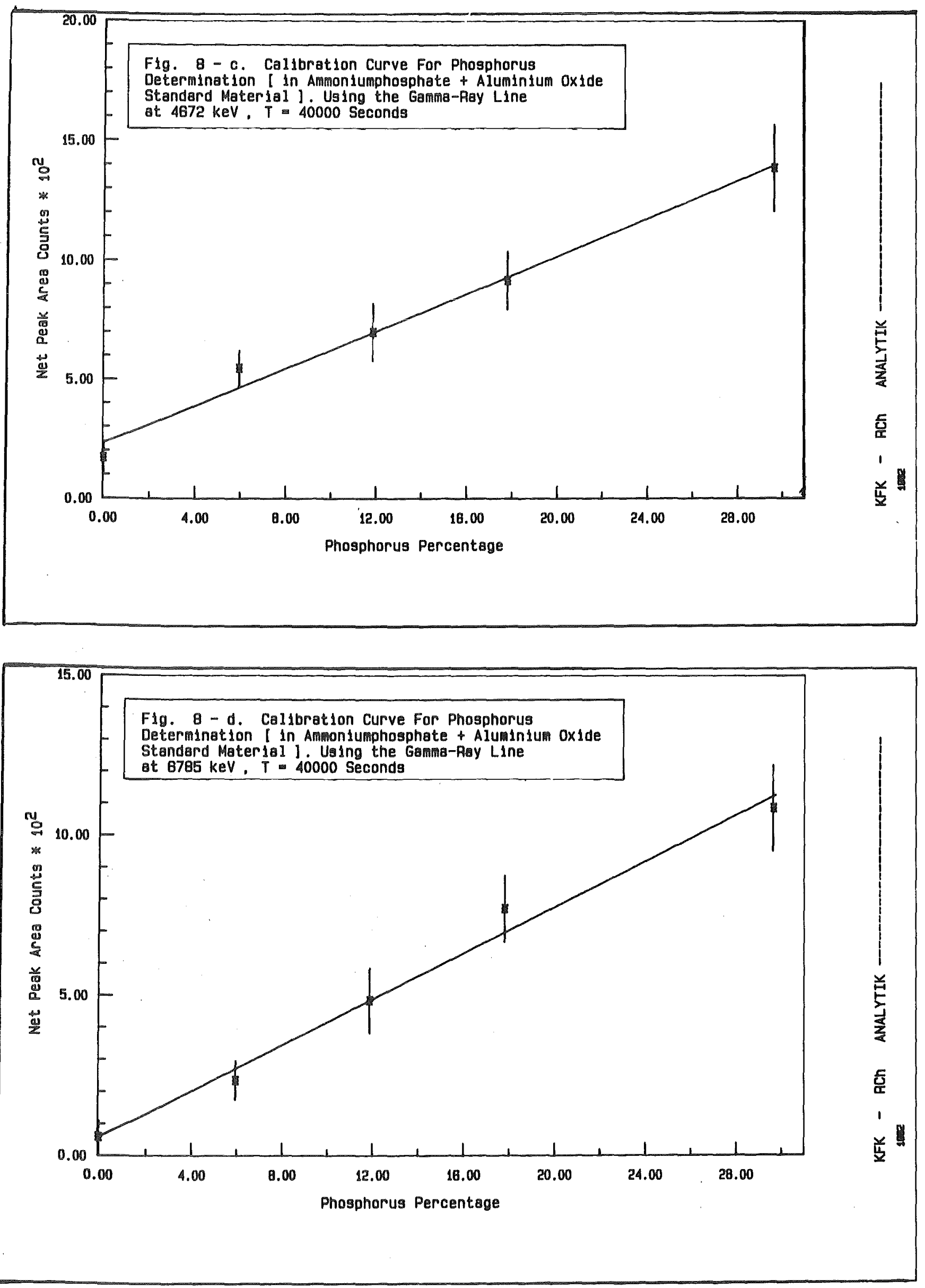


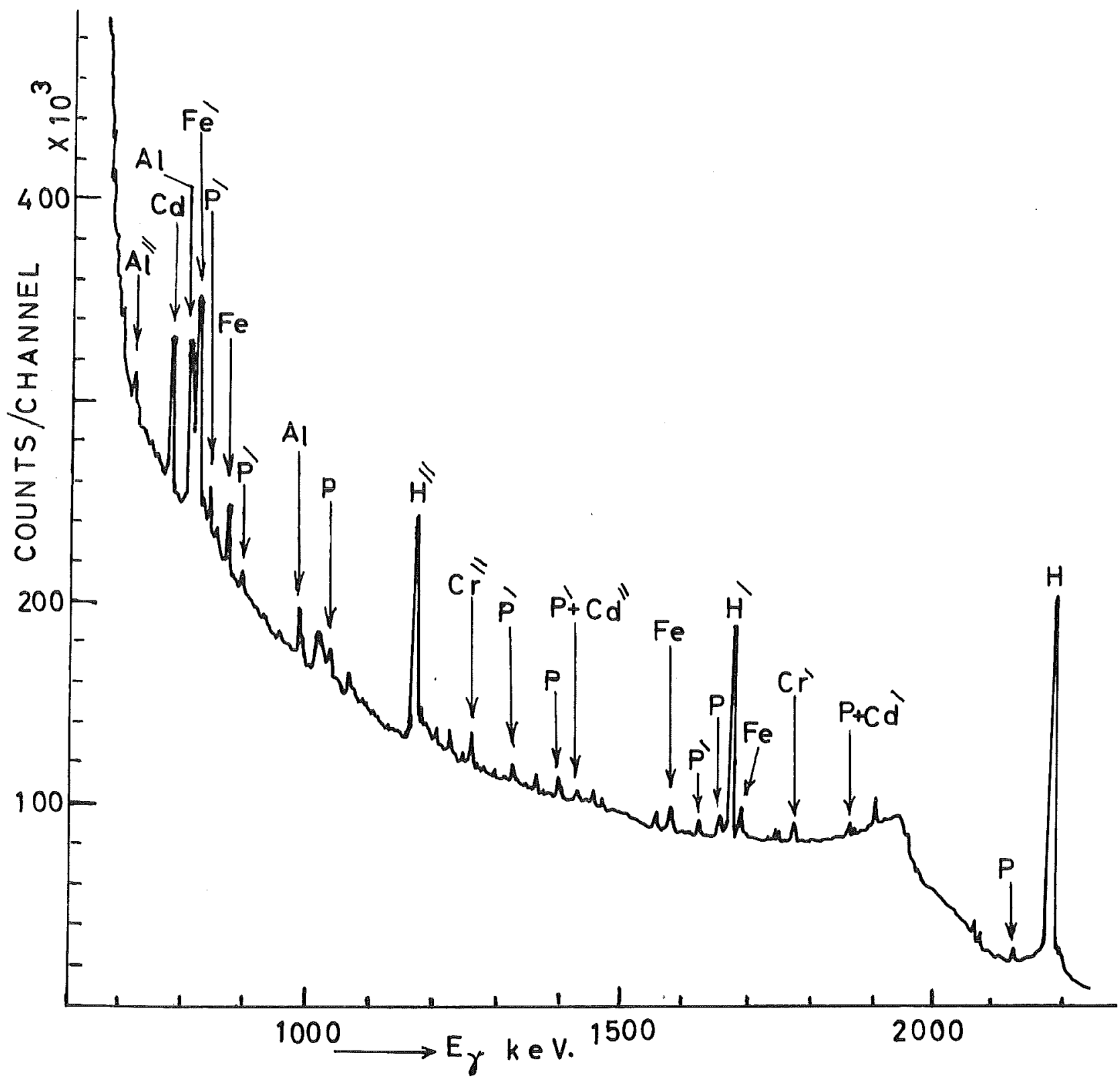

Fig. 9_a. AN EXAMPLE OF PROMPT GAMMA_RAY SPECTRA FROM THERMAL NEUTRON CAPTURE IN CALCIUM PHOSPHATE REFERENCE MATERIAL [50 Gm-9.37\% P] IN THE ENERGV RANGE $[750.2240 \mathrm{k} \mathrm{e} \mathrm{V.]}$ THE SPECTRA WERE RECORDED IN A SINGLES MODE WITH $85 \mathrm{~cm}^{3}$ Ge(Li) DETECTOR USING 252_C BASED PGNAA FACILITY. THE IRRADIATION TIME WAS 40000 SE CONDS. THE ENERGIES IN k eV COULD BE OBTAINED FOR SOME OF THE PROMINENT LINE FEATURES. THE SINGLE AND DOUBLE ESCAPE PEAKS ARE LA BELLE Q BY(/)\&(//) RESPECTIVELV. 

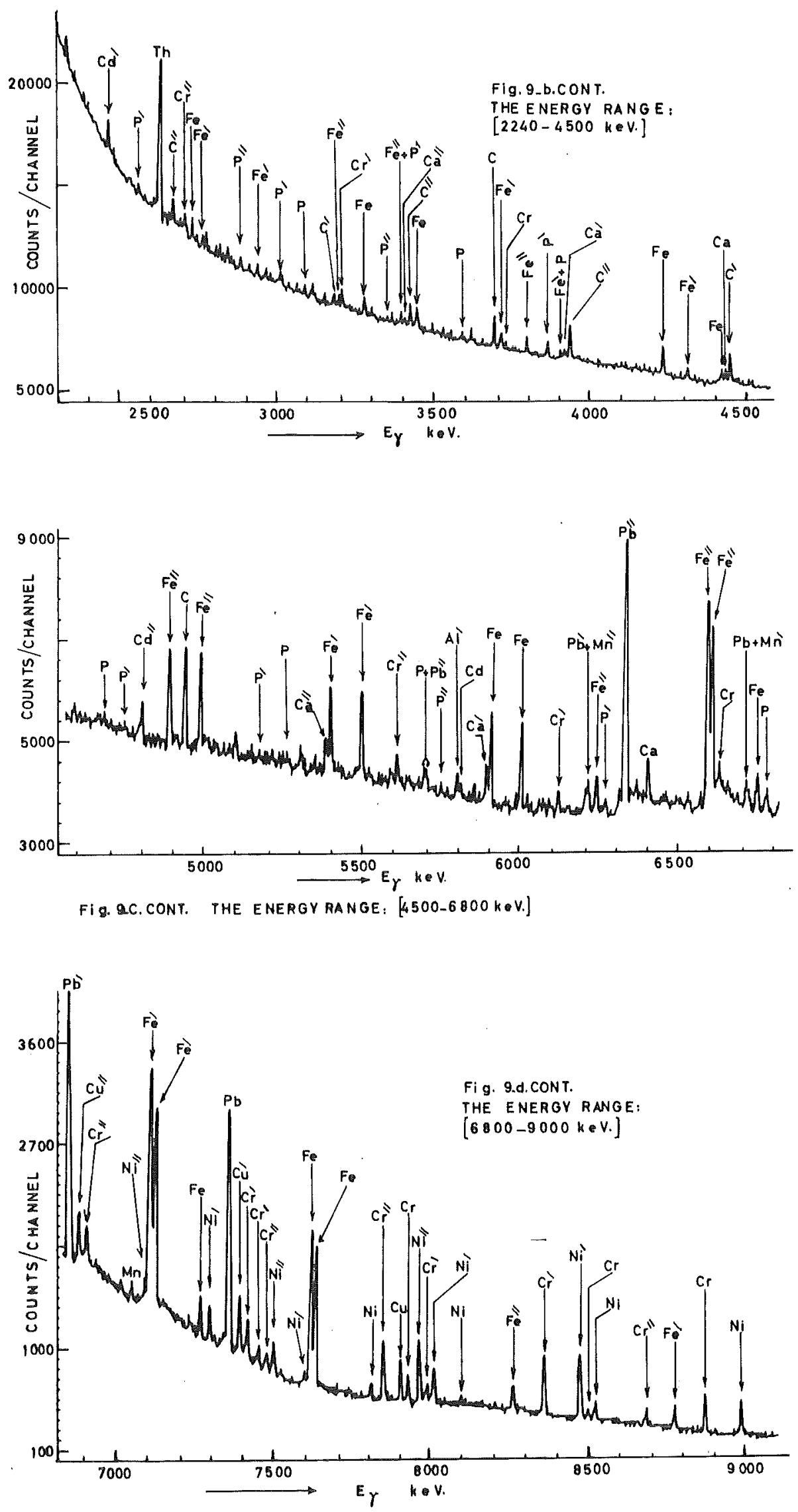

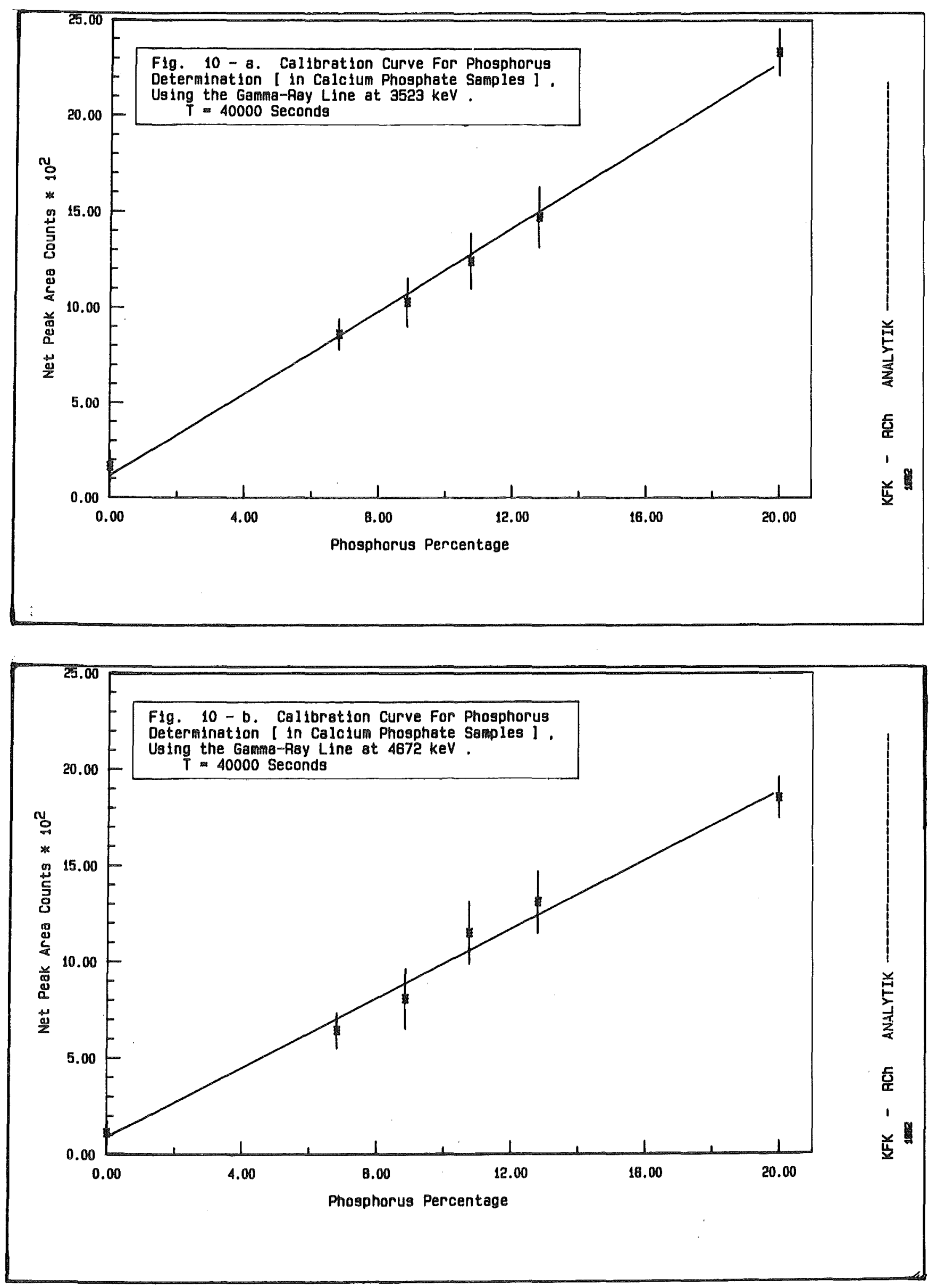